\title{
Electrospun Fibers for Solid-Phase Microextraction
}

\section{THESIS}

Presented in Partial Fulfillment of the Requirements for the Degree Master of Science in the Graduate School of The Ohio State University

\author{
By \\ Joseph William Zewe \\ Graduate Program in Chemistry
}

The Ohio State University

2010

Master's Examination Committee:

Dr. Susan Olesik, Advisor

Dr. Philip Grandinetti 
Copyright by

Joseph William Zewe

2010 


\begin{abstract}
A method of producing solid phase microextraction (SPME) fibers based on electrospinning polymers into nanofibrous mats is demonstrated. Using this method the polymer mat is attached to a stainless steel wire without the need of a binder. While applicable to any polymer that can be electrospun, SU-8 2100 , a polymeric negative photoresist, is used for this initial study. SPME devices comprised of carbon nanofibers are also illustrated by pyrolizing SU-8 to produce amorphous carbon. Nonpolar compounds, benzene, toluene, ethylbenzene, and o-xylene (BTEX) and polar compounds, phenol, 4-chlorophenol and 4nitrophenol are extracted under headspace SPME conditions. Extraction efficiencies are compared to commercial polydimethylsiloxane (PDMS), polydimethylsiloxane/divinylbenzene (PDMS/DVB) and polyacrylate (PA) fibers. For both the nonpolar and polar compounds, the carbon nanofiber based phases demonstrated enhanced or comparable (o-xylene only) extraction efficiencies. Distribution constants, $\mathrm{K}$, for benzene on the electronspun fibers are of similar magnitude to those of the compared commercial fibers and increase with carbonization temperature. Finally, the measured detection limits for all the organic compounds are similar to those measured with other SPME GC-FID methods. However, the linear dynamic range of the analysis was larger than that found for the commercial fibers.
\end{abstract}


To Bill Bailey 


\section{Acknowledgments}

First and foremost, I would like to thank my graduate advisor, Dr. Susan Olesik, for her guidance throughout the course of these past two years. Her encouragement and expertise have been most helpful, and very much appreciated.

Special thanks to Dr. Jeremy Steach. He began the initial work on the electrospun SPME devices; I am forever grateful to him for this work, as well as his input and insight over the duration of project. I also thank the Inorganic Materials Science Group in the Department of Materials Science and Engineering, specifically Krenar Shqau and Matthew Snider, for performing the porosity measurements on the electrospun nanofibers described herein. Also, I would like to thank the National Science Foundation for funding this study. My gratitude goes out to all of the members of the Olesik group for their continual support. I would like to give special recognition to James Treadway, an undergraduate in the group, with whom discussing research was always a pleasure.

Additionally, l'd like to give my thanks, and my love, to my mother and father, Sharon and Bill, as well as my brother Jim. Mom and Dad, you instilled within me the blue-collar values that I hold to so dearly today. Jim, from the rink 
to the range, you are, without a doubt, my best friend. There is nothing in this world that counts as much as family. I know that, no matter what, you will always back me. Thank you.

There are two other individuals who I would like to recognize. First, I would like to thank Jeff Rupert; my student mentor at the Indiana University of Pennsylvania, for his continued fellowship and guidance. Second, I must express my gratitude and respect to my stalwart friend, Jon Clark. Your friendship and support, personally and professionally, have been tremendously appreciated. Good luck and God bless.

Lastly, and most importantly, I would like to give thanks to God Almighty, for His many gifts and blessings in my life. Without His grace, I know I would be lost. He is my strength. May God's will be done. 


\section{Vitae}

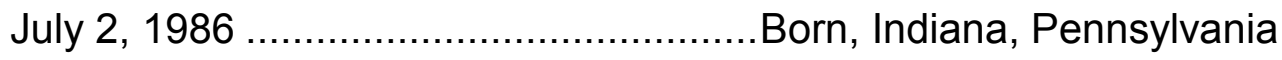

Sept. 2003-Jan. 2006 ...........................Undergraduate Research Assistant, Indiana University of Pennsylvania, Indiana, Pennsylvania

May-Aug. 2005 Undergraduate Teaching Assistant, Indiana University of Pennsylvania, Indiana, Pennsylvania

May-Aug. 2006, May-Aug. 2007 .............Chemistry/Pharmacy Intern, Diamond Pharmaceutical Services, Indiana, Pennsylvania

May 2007 Bachelor of Science, Chemistry (ACS Certified), Indiana University of Pennsylvania, Indiana, Pennsylvania

Sept. 2007-Sept. 2008 University Fellow, the Ohio State University, Columbus, Ohio

Sept. 2008-Sept. 2009 Nanoscale Science and Engineering Research Fellow, the Ohio State University, Columbus, Ohio

Sept. 2009-present Graduate Research Assistant, the Ohio State University, Columbus, Ohio

\section{Publication}

1. Zewe, J. W.; Steach, J. K.; Olesik, S. V. "Electrospun Fibers for SolidPhase Microextraction," Anal. Chem. 2010, 82, 5341-5348. 


\section{Presentations}

1. Zewe, J. W.; LeBlond, C. L. "Novel Routes to 1-Alkyl Tetrazole." 70th Annual Intercollegiate Student Chemist Convention; Collegeville, PA, April 2006.

2. Zewe, J. W.; Davis, A.; LeBlond, C. L. "A Novel Synthesis of lodohydrins Derived from Styrene and Related Compounds." $2^{\text {nd }}$ Annual Undergraduate Scholars Conference; Indiana, PA, April 2007.

3. Zewe, J. W.; LeBlond, C. L. "Computational Study of Cross-Coupling of Organic Halides." 71st Annual Intercollegiate Student Chemist Convention; Salisbury, MD, April 2007.

4. Zewe, J. W.; Steach, J. K.; Olesik, S. V. "Unique Carbon Materials for Separation Science." Ohio Innovation Summit; Dayton, OH, April 2009.

5. Zewe, J. W.; Clark, J. E.; Treadway, J. A.; Olesik, S. V. "Chromatographic Properties of Ordered Carbon Nanomaterials." The Pittsburgh Conference 2010; Orlando, FL, March 2010.

6. Zewe, J. W.; Olesik, S. V. "Molecularly Imprinted Electrospun Nanofibrous Coatings for Solid Phase Microextraction." The Pittsburgh Conference 2010; Orlando, FL, March 2010.

\section{Fields of Study}

Major Field: Chemistry 


\section{Table of Contents}

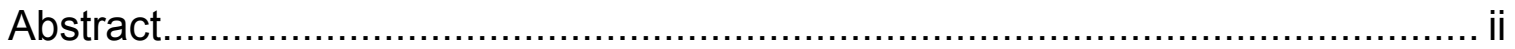

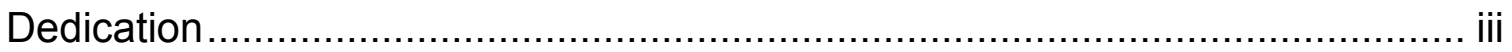

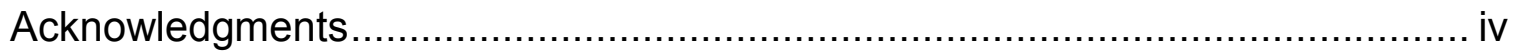

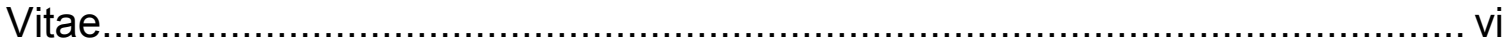

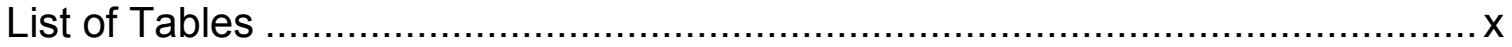

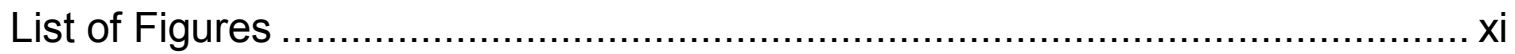

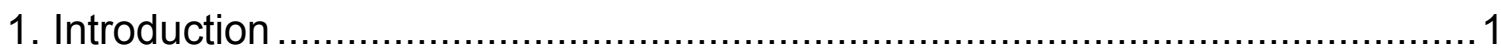

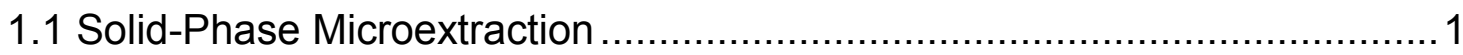

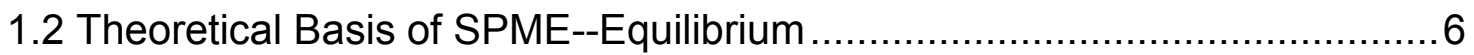

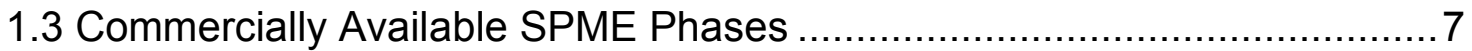

1.4 Methods of SPME Fiber Fabrication ............................................... 10

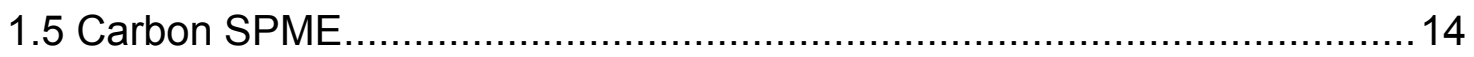

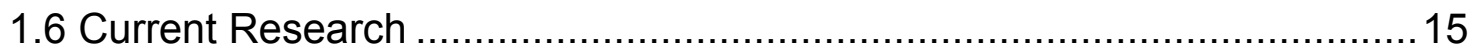

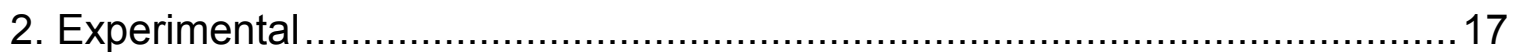

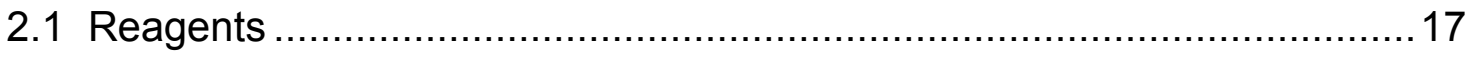

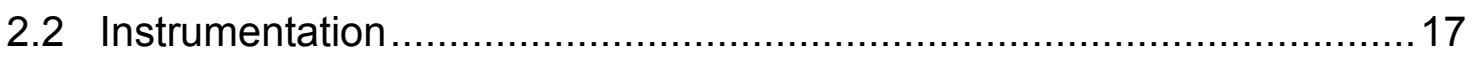




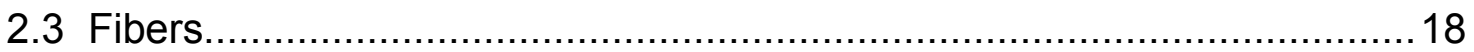

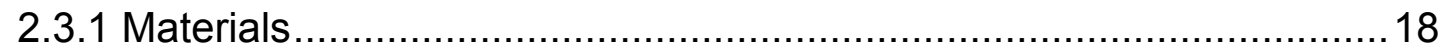

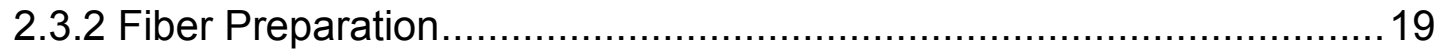

2.3.3 Pyrolysis of Electrospun SU-8 Fibers ...........................................22

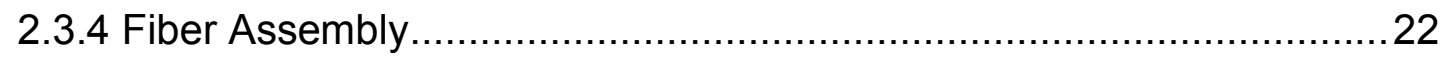

2.4 Extraction and Analysis Procedures for Nonpolar Compounds ...............23

2.5 Extraction Procedure and Analysis for Phenolic Compounds...................24

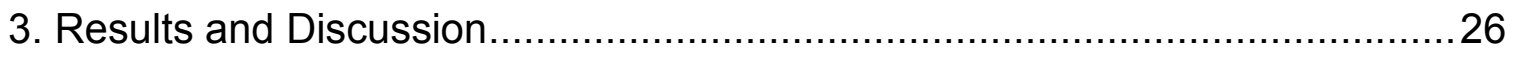

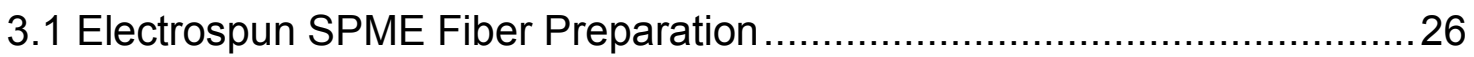

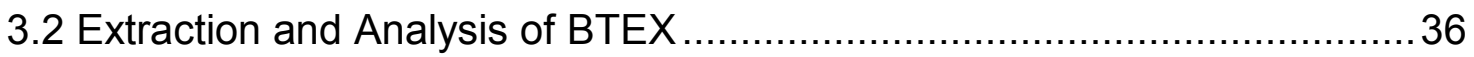

3.3 Extraction and Analysis of Phenolic Compounds .................................56

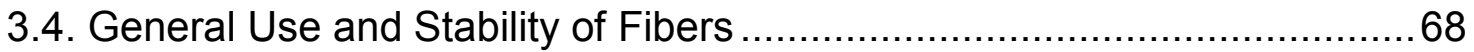

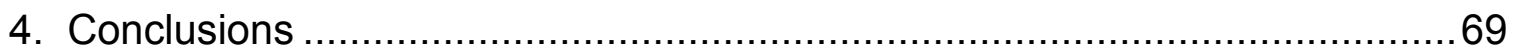

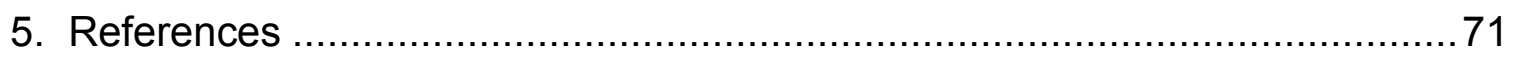




\section{List of Tables}

Table 1. Summary of Commercially Available SPME Fibers …..........................

Table 2. SEM Measured Thickness of Electrospun SPME Fibers .....................28

Table 3. Surface Area and Pore Structure of Electrospun Nanofibers ................35

Table 4. Distribution Constants for Electrospun SPME fibers for Benzene .........53

Table 5. Limits of Detection and Linear Range for Electrospun SPME for

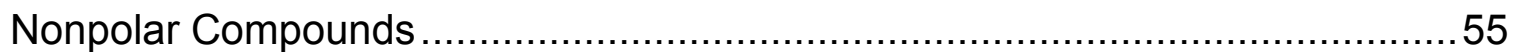

Table 6. Limits of Detection and Linear Range for Electrospun SPME for Polar

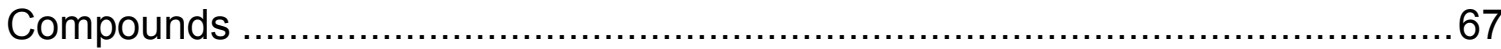




\section{List of Figures}

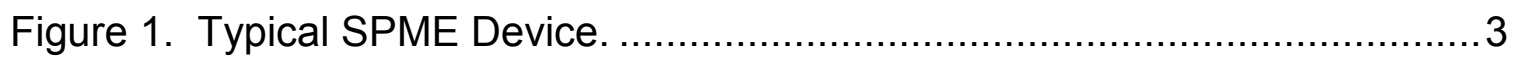

Figure 2. Direct and Headspace Extraction Modes for SPME ......................... 4

Figure 3. Fabrication of Commercial Heterogeneous Solid SPME Coatings ...... 11

Figure 4. Preparation of SPME Coatings via Sol-Gel Method..........................13

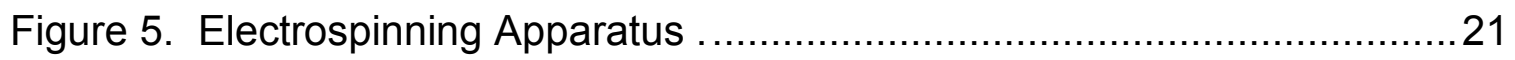

Figure 6. SEM Images of Electrospun SPME Fibers …................................29

Figure 7. Mass of Electrospun SPME Fiber Coatings ....................................30

Figure 8. Raman Spectra of Pyrolyzed Electrospun SPME Coatings ................32

Figure 9. Extraction Time Profile for BTEX for SU-8 SPME Coating. ................ 37

Figure 10. Extraction Time Profile for BTEX for $400^{\circ} \mathrm{C}$ SPME Coating..............38

Figure 11. Extraction Time Profile for BTEX for $600^{\circ} \mathrm{C}$ SPME Coating.............. 39

Figure 12. Extraction Time Profile for BTEX for $800^{\circ} \mathrm{C}$ SPME Coating ..............40

Figure 13. Extraction Efficiency of Electrospun and Commercial Fibers for

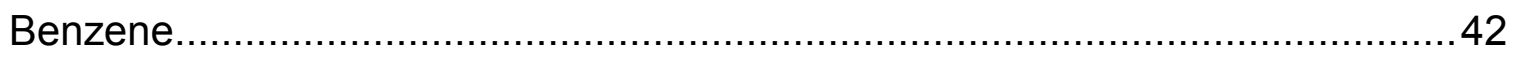

Figure 14. Extraction Efficiency of Electrospun and Commercial Fibers for

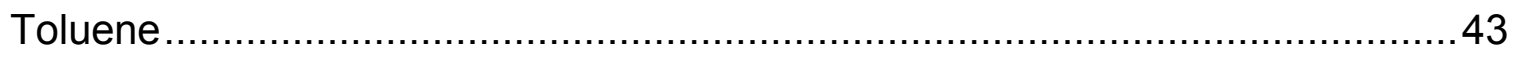

Figure 15. Extraction Efficiency of Electrospun and Commercial Fibers for

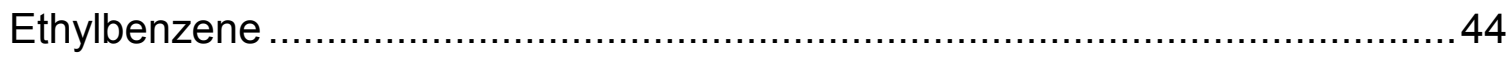


Figure 16. Extraction Efficiency of Electrospun and Commercial Fibers for o-Xylene

Figure 17. Determination of $1 / C_{f \max }$ for Benzene for SU-8 SPME fiber. ............ 48

Figure 18. Determination of $1 / C_{f \max }$ for Benzene for $400^{\circ} \mathrm{C}$ SPME fiber............. 49

Figure 19. Determination of $1 / C_{f \max }$ for Benzene for $600^{\circ} \mathrm{C}$ SPME fiber.............50

Figure 20. Determination of $1 / C_{f \max }$ for Benzene for $800^{\circ} \mathrm{C}$ SPME fiber.............51

Figure 21. Extraction Time Profile for Phenols for SU-8 SPME Coating .............58

Figure 22. Extraction Time Profile for Phenols for $400^{\circ} \mathrm{C}$ SPME Coating …........59

Figure 23. Extraction Time Profile for Phenols for $600^{\circ} \mathrm{C}$ SPME Coating ...........6 60

Figure 24. Extraction Time Profile for Phenols for $800^{\circ} \mathrm{C}$ SPME Coating ............61

Figure 25. Extraction Efficiency of Electrospun and Commercial Fibers for

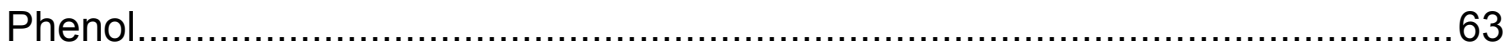

Figure 26. Extraction Efficiency of Electrospun and Commercial Fibers for

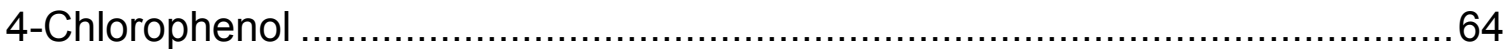

Figure 27. Extraction Efficiency of Electrospun and Commercial Fibers for

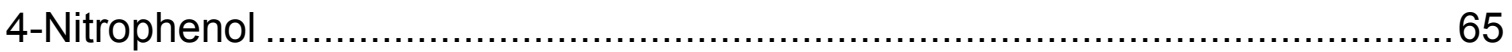




\section{Introduction}

\subsection{Solid-Phase Microextraction}

Solid-phase microextraction (SPME) is a solvent-free extraction technique that serves as an alternative to traditional extraction techniques, such as liquidliquid and solid phase extractions. ${ }^{1}$

A typical SPME device is comprised of a small amount of extractive material deposited upon a solid support, such as silica or a stainless steel wire, as illustrated in Figure 1. Sampling can be performed in either the liquid or the vapor phase and is accomplished by exposing the extracting phase of the SPME fiber to the sample matrix. There are two primary modes of extraction for SPME. The first is direct extraction, which entails placing the SPME fiber directly into the sample matrix; this mode of extraction can be utilized with both liquid and gaseous samples. The second mode is headspace extraction, wherein volatile or semi-volatile analytes are sampled from the headspace above a solid or liquid sample. In the headspace extraction mode, the fiber coating is protected against the extraction of high molecular weight species that could be present in complex sample matrices. Furthermore, the headspace extraction mode allows for facile modification of the sample matrix, such as altering the $\mathrm{pH}$, without introducing the 
fiber coating to an extremely basic or acidic environment, which could damage the fiber coating. ${ }^{1,2}$ Figure 2 illustrates the modes of SPME operation. 
Extractive Material

On Solid Support
Stainless Steel

Tubing

Plunger

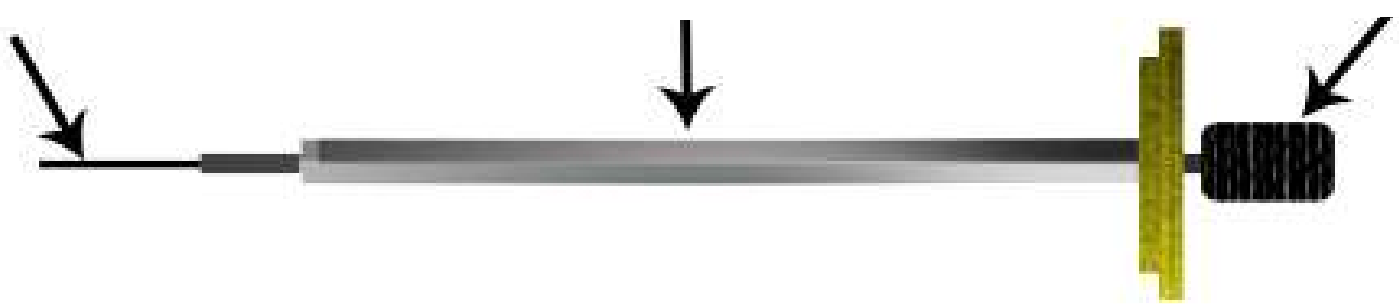

Figure 1. A typical SPME Device; the extractive coating is generally retraced within the stainless steel tubing. It is exposed during the extraction and desorption of analytes. 


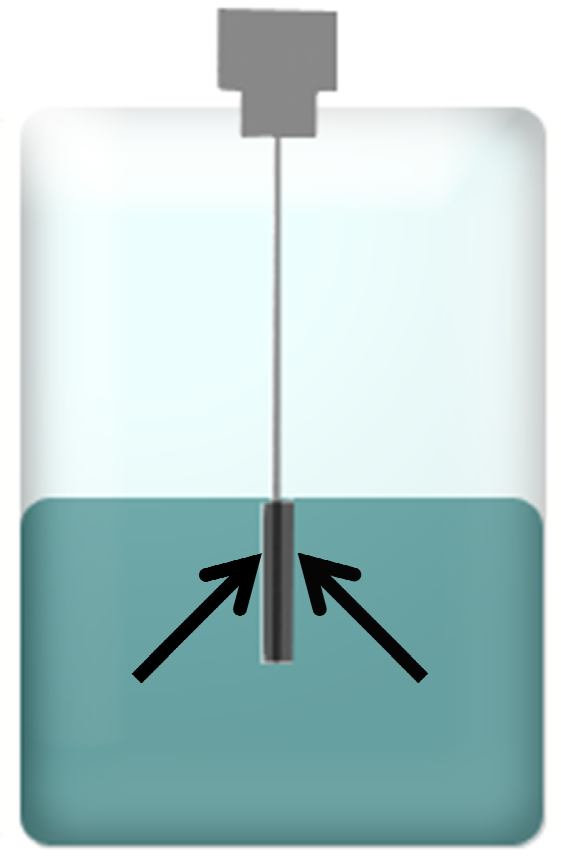

a.

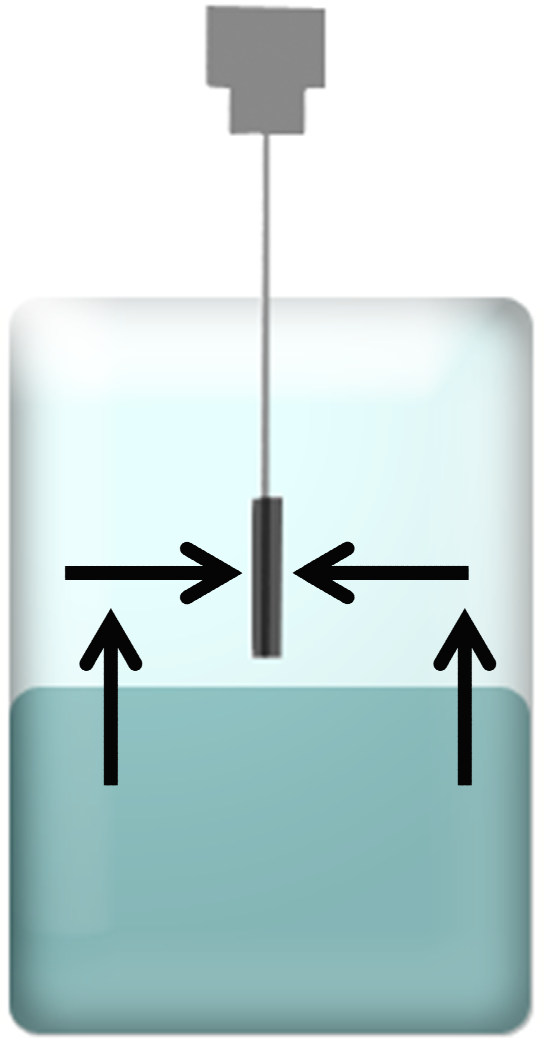

b.

Figure 2. Extraction modes for SPME: (a.) direct extraction mode and (b.) headspace extraction mode. 
SPME is an equilibrium technique; extraction of the analytes from the sample matrix occurs until equilibrium is established between the SPME fiber and the sample. The distribution ratio of the analyte between the SPME fiber coating and the sample matrix determines the amount of analyte extracted by the SPME fiber. ${ }^{1,2}$ Following extraction, the SPME fiber can be placed into the inlet of a gas chromatograph, where the analytes on the fiber are desorbed and subsequently separated and quantitated. While utilizing SPME with GC is most common, SPME can also be readily coupled with liquid chromatography. ${ }^{1,2}$

Since its introduction by Pawliszyn in the early 1990s, the popularity of SPME has expanded rapidly. ${ }^{3}$ One reason is due to the reduction in material waste as compared to traditional extraction methods, such as solid phase or liquid-liquid extraction. As no wash solutions are necessary to perform a SPME extraction, it is both more economical and environmentally friendly than other established techniques. ${ }^{4}$ Another reason is the versatility of SPME; it has been utilized in a wide variety of applications, ranging from water quality analysis ${ }^{5}$ to in-vitro and in-vivo biological fluid analysis. ${ }^{6} \mathrm{~A}$ major thrust of current SPME research entails finding ways to further expand the versatility of SPME. This can be accomplished by developing SPME fiber coatings with enhanced extraction efficiencies and selectivities, as well as coatings that are more chemically and physically robust. 


\subsection{Theoretical Basis of SPME--Equilibrium}

There are two broad types of SPME fiber coatings: liquid and solid coatings. Liquid fiber coatings are those which are either a high-viscosity rubber liquid, deposited on the solid support, or are a crystalline solid at room temperature which transition into a liquid at the elevated temperatures necessary for desorption. These fiber coatings extract analytes via an absorption mechanism, which is based upon the partitioning of a chemical species between the sample matrix and the SPME fiber coating. ${ }^{1,2}$ The equilibrium constant, $\mathrm{K}$, for absorptive fibers is shown below, in equation 1 :

$$
K=\frac{n V_{S}}{V_{f}\left(C_{0} V_{S}-n\right)}
$$

where $n$ is the amount of analyte extracted at equilibrium, $V_{s}$ is the volume of the sample, $V_{f}$ is the volume of the SPME fiber coating, and $C_{0}$ is the initial concentration of analyte in the sample. It should be noted that this equilibrium expression is for an extraction conducted in the direct mode; in the instance of a headspace extraction, the volume of the headspace and the concentration of the analyte in the headspace both must be taken into account. ${ }^{1,2}$

The second type of coating, solid fiber coatings, primarily extract analytes via adsorption. Various interactions can contribute to adsorption, including van der Waals forces, dipole—dipole interactions, and various other weak intermolecular forces. ${ }^{7}$ Unlike absorption, in adsorption, analytes sorb onto the surface of the sorbent; they do not partition into the bulk of the sorbent. Consequently, adsorptive coatings possess a limited number of surface sites for 
analytes to interact with, which means that, once a certain concentration is reached and all of the sites are filled, the fiber becomes saturated and no more analyte can be extracted by the fiber. This differs from absorptive fibers where such saturation should never occur. ${ }^{7}$ The distribution constant for solid fiber coatings in the direct extraction mode is given below:

$$
K=\frac{n V_{S}}{V_{f}\left(C_{f \max }-C_{f}^{\infty}\right)\left(C_{0} V_{S}-n\right)}
$$

Where $C_{f \max }$ is the maximum concentration of active sites on the fiber coating and $C_{f}^{\infty}$ is the analyte concentration on the fiber at equilibrium. These terms are utilized to account for the limited number of surface sites present to which analytes can adsorb. ${ }^{7}$

\subsection{Commercially Available SPME Phases}

Commercially available SPME coatings are widely available and span the scale of polarity. A list of the SPME fiber coatings available from Supelco (Bellefonte, PA) can be found in Table 1., ${ }^{1,8}$ Examples of commonly used liquid coatings include polydimethylsiloxane (PDMS) for the extraction of nonpolar compounds and polyacrylate (PA) for polar compounds. Commercially available heterogeneous solid phases include polydimethylsiloxane/divinylbenzene (PDMS/DVB) and carbowax/divinylbenzene (CW/DVB). These mixed phase coatings are comprised of porous solid particles immobilized onto the solid support by either PDMS or CW, both of which act as a glue. While both solid particles and liquid polymer are present on the fiber, adsorption via the solid 
particles has been identified as the primary mechanism of extraction. These coatings are especially adept at extracting volatile compounds and have demonstrated high selectivity. ${ }^{1,8}$ 


\begin{tabular}{|c|c|c|c|c|}
\hline $\begin{array}{l}\text { Type of } \\
\text { Coating }\end{array}$ & $\begin{array}{l}\text { Fiber Coating from } \\
\text { Supelco }\end{array}$ & Polarity & $\begin{array}{c}\text { Fiber } \\
\text { Thicknesses } \\
(\mu \mathrm{m})\end{array}$ & Applications \\
\hline \multirow[t]{2}{*}{$\begin{array}{l}\text { Liquid } \\
\text { Polymer }\end{array}$} & $\begin{array}{c}\text { Polydimethylsiloxane } \\
\text { (PDMS) }\end{array}$ & Nonpolar & $\begin{array}{l}7 \text { (bonded) } \\
30,100\end{array}$ & $\begin{array}{c}\text { Volatiles- } \\
\text { Semivolatiles } \\
\text { MW: } 125-600,80- \\
500,65-275\end{array}$ \\
\hline & Polyacrylate (PA) & Polar & 85 & Polar Semivolatiles \\
\hline \multirow[t]{3}{*}{ Solid } & $\begin{array}{l}\text { Polydimethylsiloxane/ } \\
\text { Divinylbenzene } \\
\text { (PDMS/DVB) }\end{array}$ & Bipolar & 65 & $\begin{array}{l}\text { Volatiles, Amines, } \\
\text { Nitroaromatics } \\
\text { MW: } 50-300\end{array}$ \\
\hline & $\begin{array}{l}\text { Carbowax/ } \\
\text { Divinylbenzene } \\
\text { (CW/DVB) }\end{array}$ & Polar & 75 & $\begin{array}{l}\text { Alcohols, Polar } \\
\text { Volatiles- } \\
\text { Semivolatiles } \\
\text { MW: 40-275 }\end{array}$ \\
\hline & $\begin{array}{c}\text { Divinylbenzene/ } \\
\text { Carboxen/ } \\
\text { Polydimethylsiloxane } \\
\text { (DVB/CAR/PDMS) }\end{array}$ & Bipolar & 30,50 & $\begin{array}{l}\text { Volatiles- } \\
\text { Semivolatiles } \\
\text { MW: } 40-275\end{array}$ \\
\hline
\end{tabular}

Table 1. Summary of commercially available SPME fibers from Supelco ${ }^{1,7}$ 


\subsection{Methods of SPME Fiber Fabrication}

The commercial liquid phase SPME fibers are fabricated in fiber optics towers, where thousands of meters of fused silica rod is produced by melting down a larger silica rod and drawing it to the desired thickness. Once the rod has cooled, it is drawn through an orifice containing the appropriate liquid polymer solution, which coats the rod as it is pulled through the aperture. The liquid polymer phase can then be crosslinked, in order to enhance its stability and extend its operational lifetime. ${ }^{1,8}$ However, even with the crosslinking step, liquid polymer films have a limited operational lifetime, due to the lack of a strong covalent bond between the polymer phase and the silica rod. The silica rod itself does not make a robust solid support. Furthermore, these fibers have a limited thermal stability. PDMS fibers are the most thermally stable of the commercial liquid polymer coatings; these fiber coatings can be repeatedly used with inlet temperatures approaching $300-320^{\circ} \mathrm{C} .^{1,8}$

Commercial heterogeneous solid phase coatings are prepared by a different method. ${ }^{1}$ The solid particles are suspended in a liquid polymer; the silica support is then dipped into the solution, depositing the coating onto the silica rod. This procedure is illustrated in Figure 3. Unlike the liquid polymer coatings, these mixed phases are prepared by hand in multiple steps. These phases suffer from the same issues described for the commercial liquid phase coatings. Typically, mixed phase SPME fibers demonstrate less mechanical durability than liquid phase SPME. ${ }^{1,8}$ 

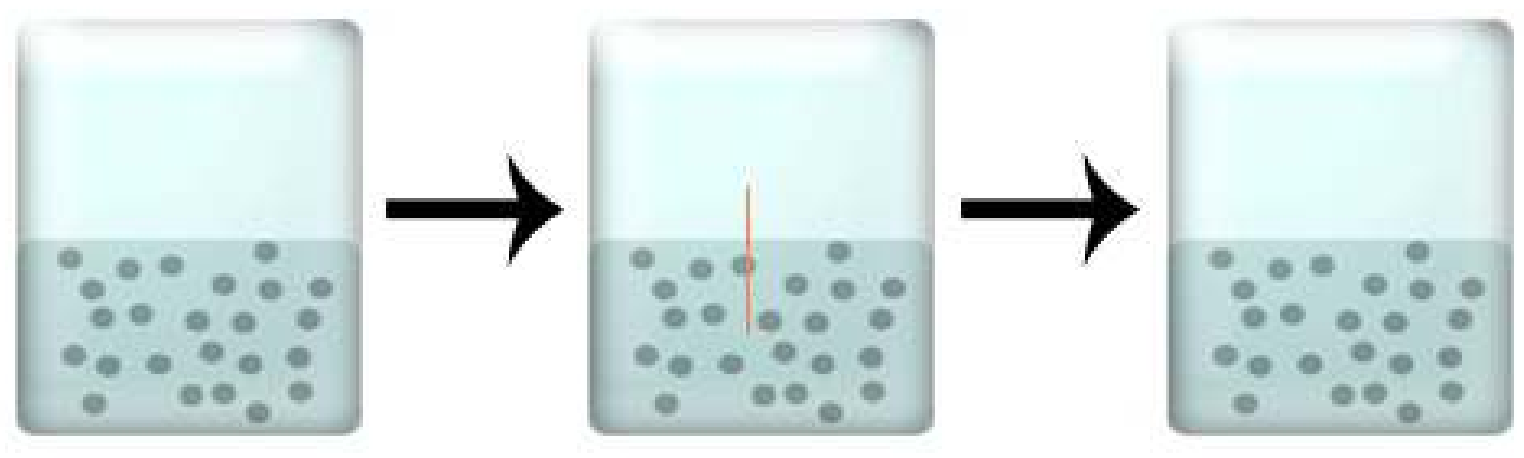

Suspension of Solid Extractive Particles in Liquid Polymer

Figure 3. Commercial heterogeneous solid coatings are made by dipping a piece of silica, which becomes the solid support, into a suspension of solid extractive particles within a liquid polymer solution. Coating thickness is controlled by how long the fiber is kept within the suspension. 
There have been several different methods of SPME fiber preparation described in the literature. ${ }^{9,10}$ One such method is the electrodeposition of a conductive polymer coating onto platinum wires. ${ }^{11}$ This has been accomplished utilizing polyaniline and zirconium oxide as fiber coatings for the extraction of phenols. ${ }^{11,12}$ This method of fabrication allows for precise control over the thickness of the phase coating. Additionally, platinum wires are a much more robust solid support than a silica rod. ${ }^{11}$

One of the most popular methods of fiber preparation has proven to be a sol-gel approach, which results in a porous organic-inorganic hybrid polymer coating that is chemically bonded to the silica rod support. ${ }^{13}$ The sol-gel method has been utilized to prepare a variety of fiber coatings, ranging from poly(ethylene glycol) (PEG), ${ }^{14}$ to low temperature glassy carbon (LTGC) SPME coatings, ${ }^{15,16}$ and an open crown ether coating. ${ }^{17}$ The key advantage over the commercial SPME fiber coatings is the covalent bond between the coating and the silica rod, which gives added thermal stability to the SPME fiber, allowing it to be desorbed at higher temperatures. A complete mechanism illustrating the solgel chemistry is shown in Figure 4. Accordingly, sol-gel coatings can be utilized for analytes with elevated boiling points relative to other fiber coatings. However, these fiber coatings are relatively physically fragile. ${ }^{13}$ 

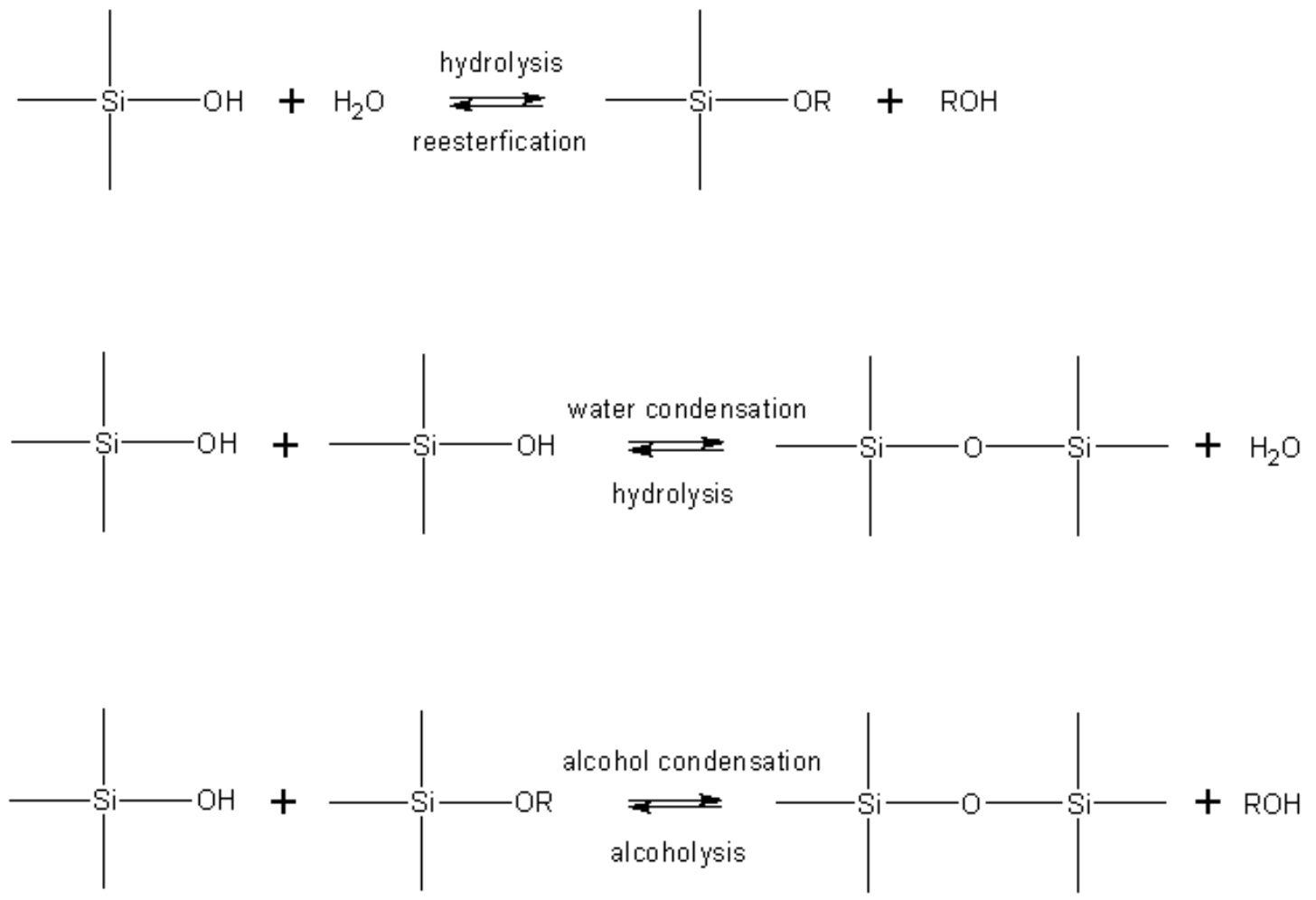

Figure 4. Typical sol-gel process. In the first step, the precursor undergoes hydrolysis. Following this reaction, polycondensation of the hydrolyzed products occurs in the second step, leading to the formation of a sol-gel network. Finally, in step three, the growing sol-gel network is bonded to the surface of the silica fiber. This produces the end result of a chemically bonded extractive phase, rather than one than is merely physically attached to the fiber. ${ }^{9}$ 
Recently, polymeric ionic liquids (PILs) have also been demonstrated to be an effective coating for SPME. These SPME fibers were fabricated by a dip coating method and proved to be effective for the selective extraction of esters. In an initial study, these coatings demonstrated high thermal stability and extraction-to-extraction reproducibility. ${ }^{18}$

\subsection{Carbon SPME}

There have been several reports of carbon-based SPME fiber coatings. ${ }^{15,16,19,20,21}$ Utilizing carbon as a SPME coating offers many advantages, such as a much increased thermal stability. Additionally, carbon SPME phases are capable of extracting both polar and non-polar compounds. A carbon extractive phase also gives a degree of shape selectivity. As previously stated, LTGC fibers prepared via a sol-gel technique have been developed and characterized. These fibers were fabricated by first pyrolyzing silica particles coated with a diethylnyl oligomer precursor to give LTGC particles, then subsequently immobilizing the LTGC onto a stainless steel fiber support. Pyrolyzation temperatures were varied, and it was demonstrated that the final processing temperature of the LTGC had a major impact on selectivity. Specifically, at higher pyrolyzation temperatures, where the surface of the LTGC particles becomes more crystalline and flat, the preferential adsorption of flat, more planar molecules is observed. ${ }^{15}$ These fibers are effective at extracting a wide variety of polar and nonpolar compounds, and showed an enhanced 
extraction efficiency and lower limits of detection relative to both liquid and solid phase commercial SPME fibers. ${ }^{15,16}$

Other types of carbon coated SPME fibers have also been explored. These include fused-silica fibers coated with carbon black, ${ }^{19}$ activated charcoal SPME fibers, ${ }^{20}$ as well as carbon nanotube-based coatings. ${ }^{21}$ Collectively, the carbon-based SPME coatings illustrate comparable or improved extraction efficiency relative to the available commercial fibers, as well as a lower limit of detection and higher thermal stability. ${ }^{19,20,21}$

\subsection{Current Research}

Herein, a new approach to coat the stainless steel wires with a mat of nanofibers is described. Electrospinning of fibers from a polymeric solution is used to generate a fiber-based coating on the stainless steel wires to be used for SPME. Electrospinning of polymeric fibers provides the capability to create micro/nanofibers through an inexpensive and simple method. Electrospun micro/nanofibers have been applied to many different applications ranging from

tissue scaffolds, ${ }^{22}$ to sensors, ${ }^{23,24,25,26}$ and electronics. ${ }^{27,28}$ In order to electrospin a polymer solution, a high electric field must be established between the solution and a conductive conductor situated some distance away. When the electric field is strong enough to overcome the surface tension of the droplet, a Taylor cone is formed. Following the creation of the Taylor cone, polymeric nanofibers are ejected toward the conductive collector. ${ }^{29}$ With this coating method, many different polymers and polymer blends can be used to fabricate SPME fibers with 
various chemical compositions. This method provides an approach to generate high surface area fibers and the ability to alter the SPME fiber composition by changing the polymer solution for electrospinning.

In this study, nanofibrous SPME fiber coatings are generated by electrospinning SU-8 2100, a negative photoresist. The parameters for the optimization of electrospinning SU-8 were previously investigated and were applied here to generate the fiber coating. ${ }^{30}$ Carbon nanofiber based coatings are prepared by pyrolyzing the SU-8 nanofibers. The extraction characteristics of the SU-8 and pyrolyzed electrospun-coated wires are investigated for nonpolar (benzene, toluene, ethylbenzene and o-xylene) and polar (phenol, 4chlorophenol, and 4-nitrophenol) compounds under headspace extraction conditions. 


\section{Experimental}

\subsection{Reagents}

Benzene (99.9\%), toluene (99.8\%), ethylbenzene (99.8\%), o-xylene (98\%), phenol, 4-chlorophenol and 4-nitrophenol were used for initial extractions and were purchased through Sigma-Aldrich. Dichloromethane was used to prepare the solutions for benzene, toluene, ethylbenzene, and o-xylene, while HPLC-grade methanol was used to prepare the phenolic solutions. All chemicals were used without further purification.

\subsection{Instrumentation}

All compounds extracted via the SPME fibers were analyzed using a Hewlett-Packard 5890 Series II Plus gas chromatograph (GC) with a pressure controlled split/splitless injector port and flame ionization detector (FID). An injection sleeve with an inner diameter of $0.75 \mathrm{~mm}$ was utilized, coupled with a HP-5MS GC capillary column ((5\%-Phenyl)-methylpolysiloxane stationary phase, $0.25 \mu \mathrm{m}$ film thickness, $30 \mathrm{~m}$ length, $0.255 \mathrm{~mm}$ inner diameter) from Agilent Technologies. Both 100- $\mu$ m polydimethylsiloxane (PDMS) and Stableflex 65$\mu \mathrm{m}$ polydimethylsiloxane /divinylbenzene (PDMS/DVB) fibers from Supelco were 
compared to the electrospun fibers for the analysis of nonpolar compounds. For the extraction of phenols, the performance of an $85-\mu \mathrm{m}$ polyacrylate (PA) commercial fiber was compared to the electrospun fibers. All commercial fibers were conditioned in the inlet at the specified temperature and time recommended by Supleco or until a stable baseline was achieved.

Raman spectra of the electrospun nanofiber-coated wires were recorded using a Renishaw-Smith Detection Combined Raman-IR Microprobe. A 50X microscope objective and a wavelength of $785 \mathrm{~nm}$ were used. A Hitachi S-4300 scanning electron microscope (SEM) was used to study the microscopic and nanostructure of the fibers. A Micromeritics ASAP 2020 gas adsorption analyzer was utilized to determine the sorption isotherms of nitrogen at $77.35 \mathrm{~K}$. From these data the surface area and porosity of the electrospun SU-8 and carbon nanofibers were determined.

\subsection{Fibers}

\subsubsection{Materials}

SU-8 2100 is a negative photoresist purchased from Microchem Corp. (Newton, MA). Negative photoresists are comprised of a base polymer and a photoreactive cross-linking agent. Upon exposure to UV light, the resist hardens, as polymerization by the UV-active crosslinking agent occurs. ${ }^{31}$ The SU-8 2100 was dissolved in cyclopentanone (Aldrich) to prepare the polymer solution used to electrospin fibers onto the stainless steel wires. The solution was 
magnetically stirred until a homogenous solution was obtained. The electrospinning solutions were drawn into $10 \mathrm{~mL}$ syringes and all air bubbles were expelled prior to electrospinning. Preparation of the SU-8 solutions was conducted under yellow light to ensure that the solution did not become prematurely crosslinked. The stainless steel wires (diameter of $\sim 127 \mu \mathrm{m}$ ) were purchased from Small Parts (Miami Lakes, FL) and used as the collector for the electrospun nanofibers.

\subsubsection{Fiber Preparation}

The stainless steel wires were cut into $1.5 \mathrm{~cm}$ lengths and cleaned by rinsing with methanol and then drying in an oven at $80^{\circ} \mathrm{C}$ for 30 minutes before electrospinning. Previously determined parameters to electrospin a $75 \%$ SU-8 2100 solution were used to generate the nanofibers. ${ }^{20}$ The apparatus used to electrospin the fibers onto the stainless steel wire is shown in Figure 5. A Spellman CZE 1000R high voltage source (Hauppauge, NY) was used to supply the voltage needed to electrospin the fibers onto the stainless steel wires. During each experiment, a single stainless steel wire was connected to the ground wire by an alligator clip. A voltage of $9 \mathrm{kV}$ was applied. A Harvard Model 33 dual syringe pump was used to control the flow rate of the SU-8 2100 solutions. A flow rate of $0.02 \mathrm{~mL} / \mathrm{min}$ was chosen. The distance between the syringe tip and the collector wire was $10 \mathrm{~cm}$. All electrospinning experiments were performed under yellow light to ensure that the SU-8 solution did not become crosslinked. All fibers were electrospun for 30 seconds to create the fiber coating on the 
stainless steel wire. The electrospinning time can be varied to give different coating thicknesses if desired; longer electrospinning times give thicker coatings. After electrospinning onto the stainless steel wire, all fibers were exposed to UV radiation (Uvitron, SunRay 400SM flood lamp 320-390 nm, 400 watts) for a period of 5 minutes to crosslink the electrospun SU-8 fibers onto the stainless steel fibers. This crosslinking step was essential for the production of carbon nanofibers. Without this step, individual fibers combined with other fibers to yield a flat carbon surface when pyrolyzed. ${ }^{20}$ 


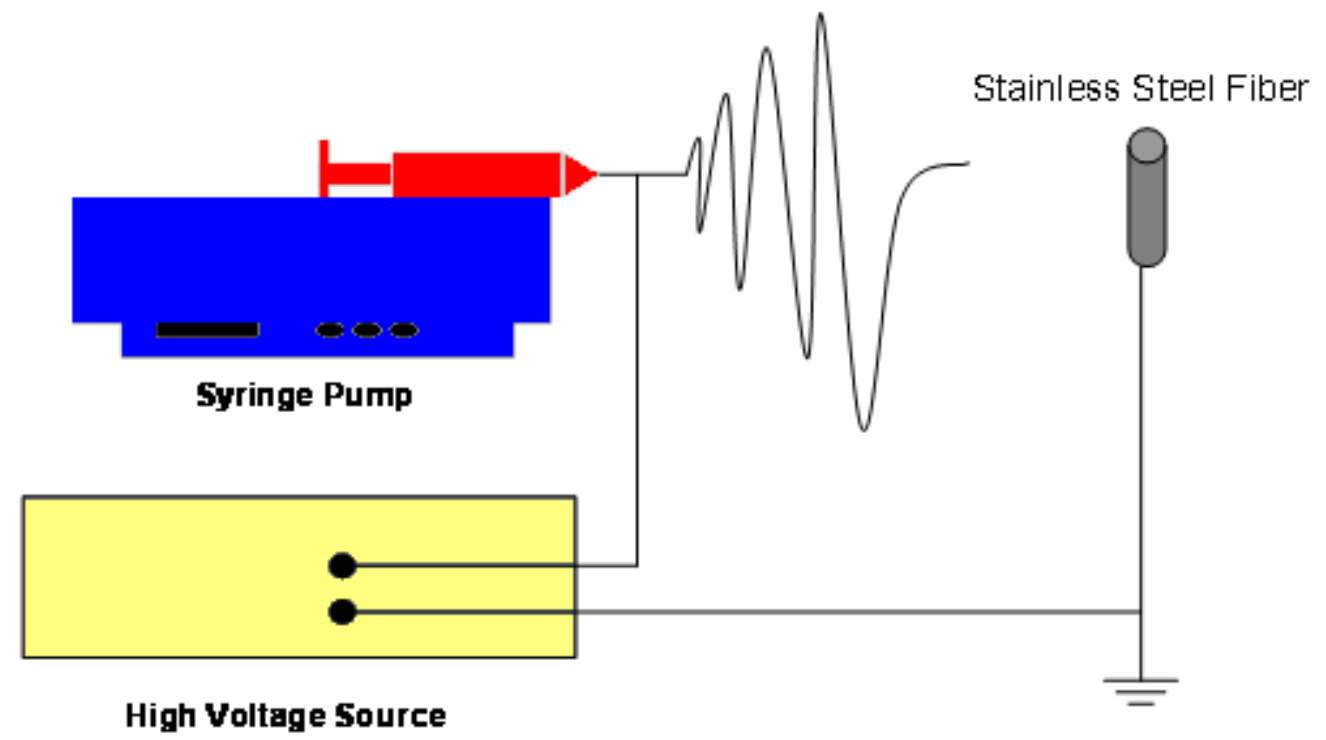

Figure 5. Apparatus used to create the electrospun nanofiber-coated solid phase microextraction fibers. 


\subsubsection{Pyrolysis of Electrospun SU-8 Fibers}

To convert the SU-8 polymer to carbon, the coated wires were pyrolyzed in a Lindberg/Blue TF55030A quartz tube furnace. Temperatures of 400, 600, and $800^{\circ} \mathrm{C}$ were chosen as final pyrolysis temperatures for extraction studies. Once the sample was placed in the quartz tube, a forming gas mixture $\left(95 \% \mathrm{~N}_{2}\right.$ and $5 \% \mathrm{H}_{2}$ ) initially purged the tube for 20 minutes and continued to flow through the tube for the entire duration of the pyrolysis. The temperature was ramped at $1^{\circ} \mathrm{C} / \mathrm{min}$ to the final temperature of 400,600 , or $800^{\circ} \mathrm{C}$ and held for a minimum period of 5 hours before the pyrolysis was stopped. After the furnace was turned off, the fibers were allowed to cool to room temperature $\left(25^{\circ} \mathrm{C}\right)$ under a constant flow of forming gas before they were removed.

\subsubsection{Fiber Assembly}

Commercial SPME fiber assemblies were modified so that the electrospun-fiber coated stainless steel wires could be attached. This was accomplished by using a high-temperature epoxy (Epoxy Technology, Billerica, MA). To cure the epoxy, the coated wires were placed in an oven at $80^{\circ} \mathrm{C}$ for 1 hour. The electrospun-fiber coated wires were then transferred to the inlet on the $\mathrm{GC}$, where the inlet temperature was set at $300^{\circ} \mathrm{C}$ or $320^{\circ} \mathrm{C}$. The coated SPME wires were held in the inlet for a minimum of 30 minutes or until a steady signal baseline was achieved. 


\subsection{Extraction and Analysis Procedures for Nonpolar Compounds}

All extractions were carried out in $40 \mathrm{~mL}$ EPA vials capped with EPA PTFE/silicone (10/90) septa (National Scientific, Rockwood, TN) at room temperature $\left(25^{\circ} \mathrm{C}\right)$. The volume of water was held constant at $25 \mathrm{~mL}$ for all extractions, leaving $15 \mathrm{~mL}$ headspace volume. Nanopure water (18 M $\Omega-\mathrm{cm})$ was utilized in all extractions. An egg-shaped Teflon stir bar (Fisher Scientific, Hanover Park, IL) with dimensions of 0.5 in $\times 0.25$ in was used to agitate the solution for the extractions. The stirring rate was held constant at $50 \%$ power with an IKA C-MAG HS7 stir plate.

Extraction time profiles were initially determined for benzene, toluene, ethylbenzene, and o-xylene (BTEX). For each analyte, a 10,000 ppm solution was prepared in dichloromethane. The nanopure water was spiked with the $10,000 \mathrm{ppm}$ analyte solution to yield a final concentration of $40 \mathrm{ppm}$. Extractions were performed for each analyte. This concentration was chosen because the equilibration time at lower concentrations was found to take several hours. The vial was capped and the spiked solution was stirred for 20 minutes after which the fiber was then exposed to the headspace for a set of selected extraction times (0 to 90 minutes) to determine the extraction time profile. Immediately after extraction, the fiber was removed and transferred to the GC-FID for analysis. The injection port and detector temperatures were held constant at $280^{\circ} \mathrm{C}$ and $300^{\circ} \mathrm{C}$, respectively. The temperature program started at $30^{\circ} \mathrm{C}$ was held constant for 1 minute and then was ramped at $5^{\circ} \mathrm{C} / \mathrm{min}$ to a final temperature of 
$150^{\circ} \mathrm{C}$ that was held for 5 minutes. The total desorption time was 30 minutes which was the time to complete the chromatogram.

For comparison studies with the commercial fibers, $40 \mathrm{ppm}$ solutions of BTEX compounds were extracted for 60 minutes. All other parameters were the same as those used for the extraction time profiles, except for the PDMS/DVB commercial fiber, for which the inlet temperature was held at $270^{\circ} \mathrm{C}$, the maximum operating temperature reported for this fiber by Supelco. The inlet temperature was increased to $300^{\circ} \mathrm{C}$ for the electrospun-fiber coated wires.

\subsection{Extraction Procedure and Analysis for Phenolic Compounds}

The extraction time profiles for the phenolic compounds were determined by using a mixture of phenol, 4-chlorophenol, and 4-nitrophenol. All extractions were carried out using the same vials, stir bar, and stir plate as was used for the extraction of BTEX. A 100 ppm solution of the above phenolic compounds was prepared in methanol. To perform the extractions, the $\mathrm{pH}$ of nanopure water was changed to $\mathrm{pH} 1$ via the addition of concentrated hydrochloric acid; 10 grams of sodium chloride was added to this acidic solution to ensure a saturated solution. ${ }^{11,12}$ The stir plate was set at a power level of $80 \%$; this stir rate was used for all the phenolic extractions. Once the $25 \mathrm{~mL}$ of $\mathrm{pH} 1$ solution and $\mathrm{NaCl}$ were added to the extraction vials, the available headspace extraction volume was $10 \mathrm{~mL}$. The solution was spiked with the $100 \mathrm{ppm}$ phenolic mixture to give a concentration of $0.4 \mathrm{ppm}$. After spiking the solution, the vial was capped, and the solution was stirred for 20 minutes prior to the insertion of the SPME fiber. The 
electrospun-coated SPME fiber was then inserted through the septa and the extraction was performed. After each extraction, the fiber was immediately placed in the inlet of the GC for analysis. The inlet temperature and detector temperatures were both set to $320^{\circ} \mathrm{C}$. The $\mathrm{GC}$ temperature program included holding the oven temperature initially at $80^{\circ} \mathrm{C}$ for 2 minutes, then increasing the temperature at a rate of $10^{\circ} \mathrm{C} / \mathrm{min}$ to a final temperature of $260^{\circ} \mathrm{C}$, which was held for 5 minutes. The total desorption time was 25 minutes which was the total time for each chromatogram.

For comparison studies with the commercial PA fiber, a $0.4 \mathrm{ppm}$ phenolic solution was extracted for 60 minutes. The GC inlet temperature was $320^{\circ} \mathrm{C}$ for the electrospun-coated fibers while the inlet temperature for the PA fiber was held at $280^{\circ} \mathrm{C}$. All other chromatographic parameters were kept the same. 


\section{Results and Discussion}

\subsection{Electrospun SPME Fiber Preparation}

The optimized conditions used to make the SU-8 nanofibers produced a

mat composed of solid fibers with diameters of $\sim 400 \mathrm{~nm} \cdot{ }^{30}$ The structure of the mat provides a porous network for extractions and the fibers provide a high surface area. An electrospinning time of 30 seconds was initially chosen to characterize the extraction properties of both the SU-8 2100 and the pyrolyzed SU-8 electrospun-fiber coated wires as a novel SPME fiber coating. For these conditions, the fiber coating on the SU-8 coated stainless steel wire was approximately $18.8 \pm 2.3 \mu \mathrm{m}$ (Table 2). Figure $6 \mathrm{~A}$ shows an SEM image of electrospun SU-8 fibers on a stainless steel wire for these conditions.

Pyrolysis of electrospun SU-8 coated wires is a simple way to generate a carbon fiber-coated surface for SPME. Figure 6B-D and Table 2 show the SEM images and film thicknesses obtained for the pyrolyzed fibers produced from electrospinning SU-8 onto the stainless steel fibers. Both the diameter of the nanofibers and the overall thickness of the nanofibrous mat decreased with increasing processing temperature. The mass of the fiber coating was found to decrease linearly with increasing pyrolysis temperature (Figure 7). For example, 
a SU-8 mat of $0.52 \mathrm{mg}$ is converted to $0.33 \mathrm{mg}$ of carbon by pyrolysis to $600^{\circ} \mathrm{C}$ and $0.20 \mathrm{mg}$ of carbon by pyrolysis to $800^{\circ} \mathrm{C}$. However, as will be described later, the surface area increases with processing temperature. The fiber coating thickness can be tailored for each temperature by varying the electrospinning time; an increased electrospinning time gives an increased mat thickness. ${ }^{30}$ 
Fiber

SU-8

$400^{\circ} \mathrm{C}$

$600^{\circ} \mathrm{C}$

$800^{\circ} \mathrm{C}$
Fiber Coating Thickness $(\mu \mathrm{m})$
Nanofiber diameter (nm)

$18.8 \pm 2.3 \quad 414 \pm 150$

$11.4 \pm 1.0$

$370 \pm 100$

$6.2 \pm 0.7$

$330 \pm 70$

$3.7 \pm 0.2$

$300 \pm 70$

Table 2. Summary of the SEM measured fiber thickness for the electrospun coated SPME fibers. Fibers were coated by electrospinning onto the stainless fiber for 30 seconds. 


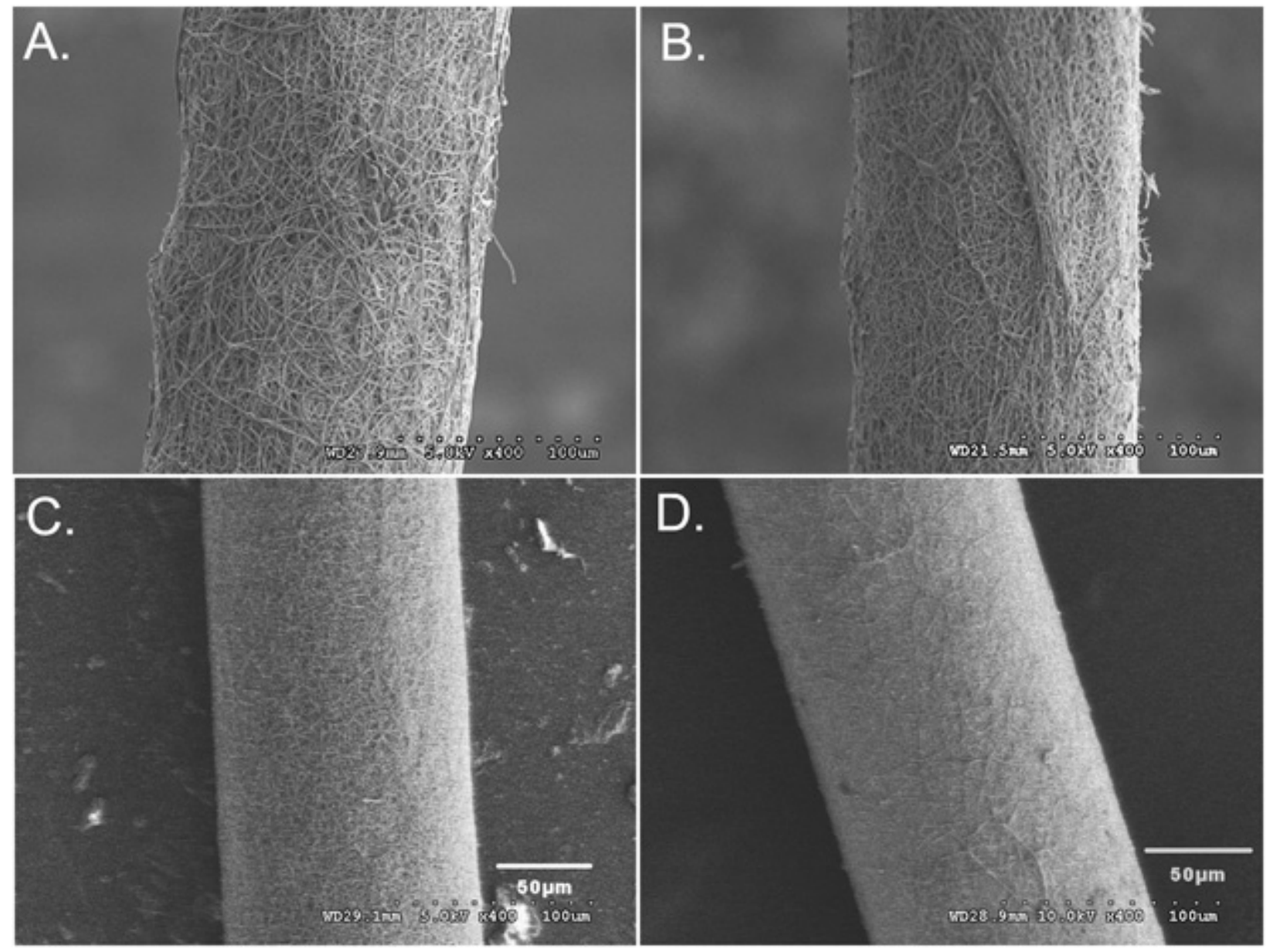

Figure 6. SEM images of the electrospun coated SPME fibers and the different temperatures used to produce these devices: (A.) SU-8 (B.) $400^{\circ} \mathrm{C}$ (C.) $600^{\circ} \mathrm{C}$ (D.) $800^{\circ} \mathrm{C}$. 


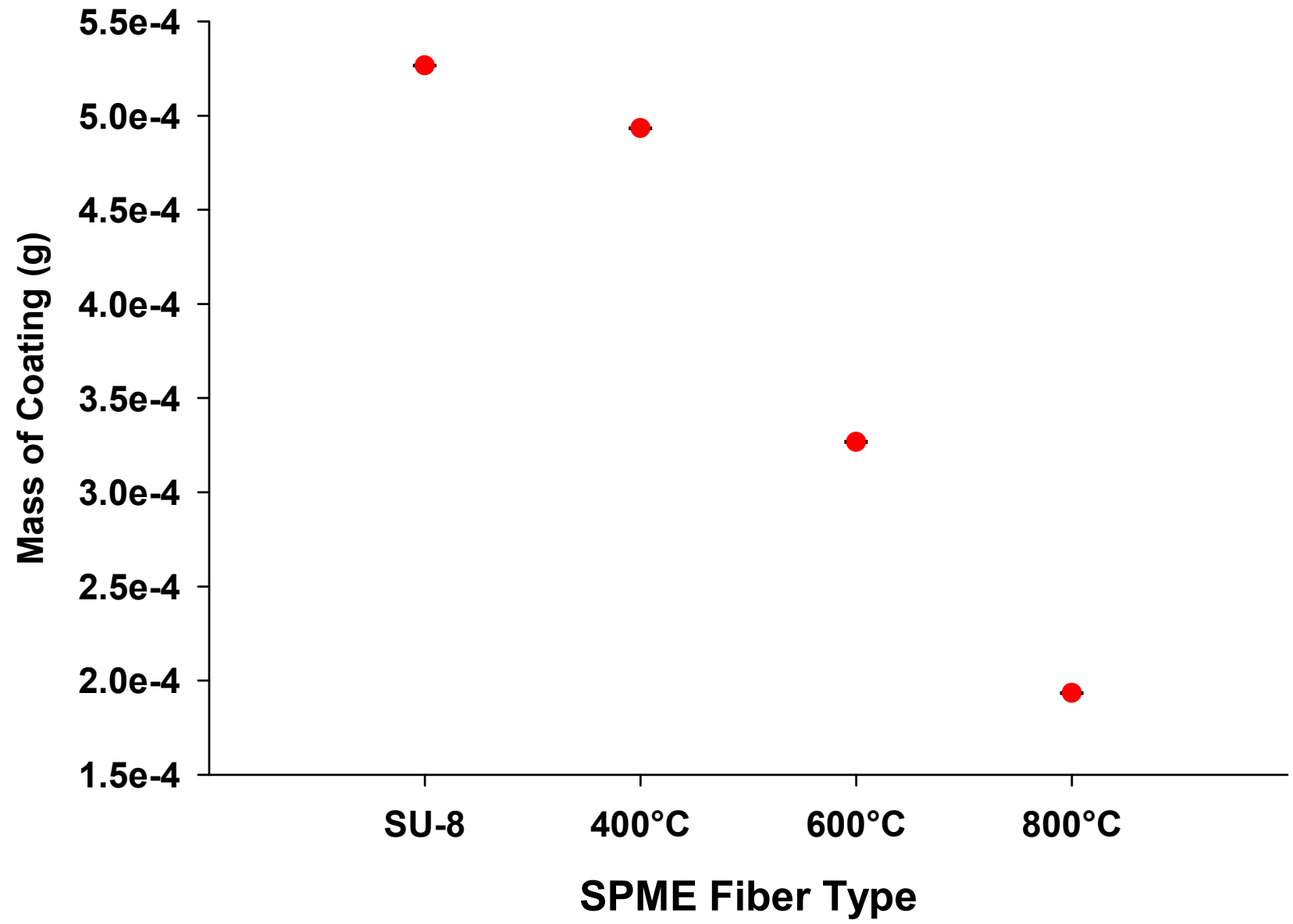

Figure 7. Mass of the electrospun fiber coating for each SPME fiber. Note the linear relationship for the carbon nanofiber coated SPME fibers. 
Raman spectra of the electrospun-coated SPME fibers were measured after pyrolysis at $600^{\circ} \mathrm{C}$ and $800^{\circ} \mathrm{C}$ to assess the extent of conjugation and disorder of the carbon surface. The Raman spectra of the $600^{\circ} \mathrm{C}$ and $800^{\circ} \mathrm{C} \mathrm{SU}$ 8 electrospun-coated SPME fibers are available in Figure 8. Both spectra displayed the characteristic bands at $1572 \mathrm{~cm}^{-1}$ ( $G$ band, $E_{2 g 2}$ mode of graphite) and $1360 \mathrm{~cm}^{-1}$ (D band, disorder induced) of amorphous carbon. 

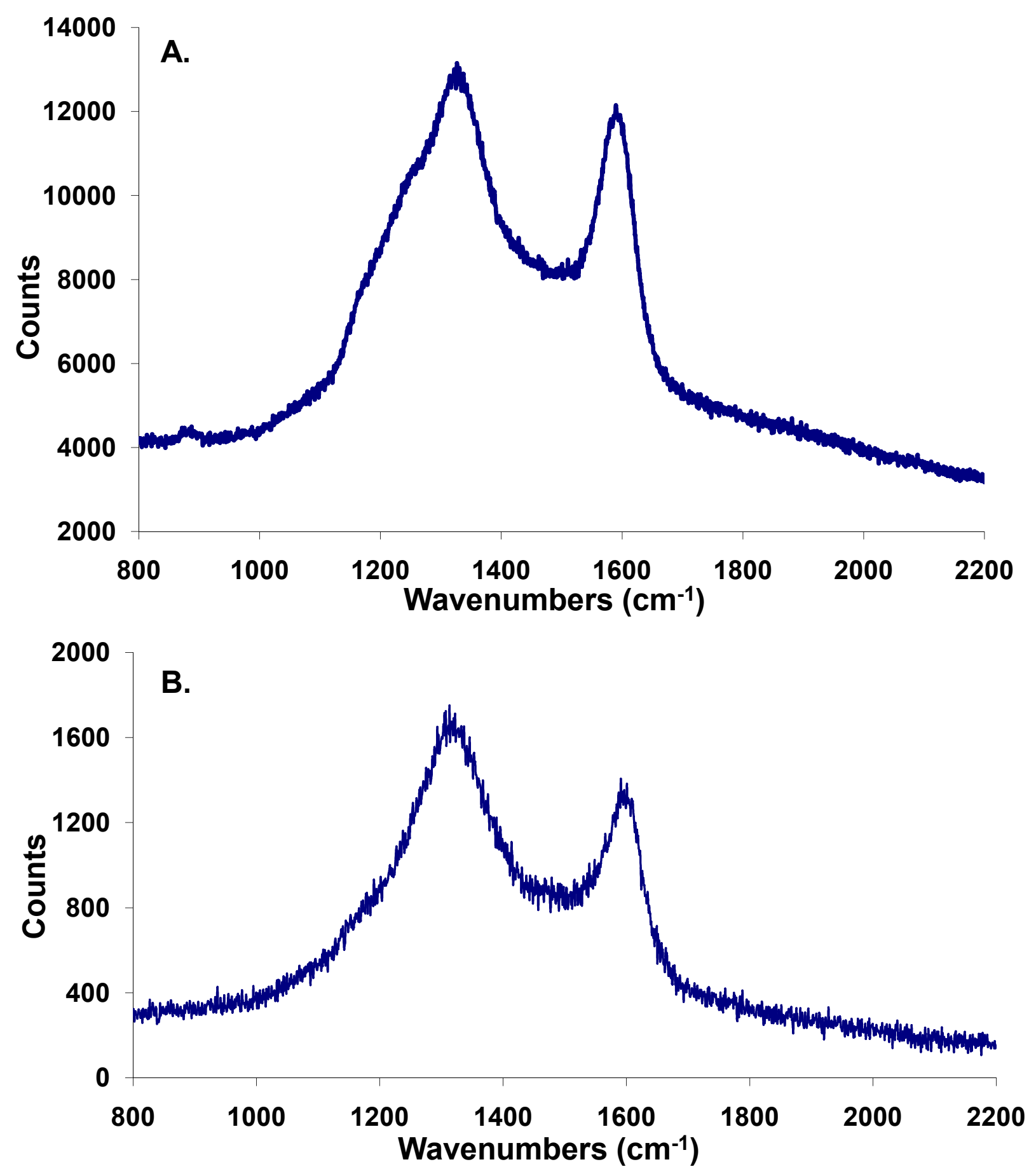

Figure 8. Raman spectrum of electrospun fiber coated SPME wires processed to (A.) $600^{\circ} \mathrm{C}$ and (B.) $800^{\circ} \mathrm{C}$. 
For more than thirty years, it has been generally accepted that the inplane microcrystallite size, $L_{\alpha}$, of disordered carbon can be calculated using the ratio of the two Raman bands through equation 3:

$$
\frac{I_{G}}{I_{D}}=\frac{C(\lambda)}{L_{\alpha}}
$$

where $I_{G}$ is the intensity of the $G$ band; $I_{D}$ is the intensity of the $D$ band and $C$ is a constant that varies with the incident laser wavelength. ${ }^{32,33}$ For the laser excitation wavelength used herein, $C$ is $133 .{ }^{34}$ The value of the ratio, $I_{D} / I_{G}$, of the integrated peak areas is also proportional to the degree of structural order. ${ }^{35}$ The integrated areas of the Raman bands were determined using a Gaussian-Lorentz fit. The ratios determined from the peak areas for the $600^{\circ} \mathrm{C}$ and $800^{\circ} \mathrm{C}$ electrospun fibers were 1.08 and $1.36 .{ }^{36}$ Using equation 3 , the microcrystallite sizes of carbon processed to 600 and $800^{\circ} \mathrm{C}$ decreased from 12.3 and $9.8 \mathrm{~nm}$, respectively.

The Brunauer, Emmett, Teller (BET) method was used to calculate the surface area of the nanofiber while the Barrett-Joyner-Halenda method (BJH) method was used to determine the porosity of the fibers (Table 3). The SU-8 fibers have low surface area and minimal porosity while the surface areas of the carbon nanofibers $\left(400,600,800^{\circ} \mathrm{C}\right.$ processed fibers) increase with processing temperature and the fibers have substantial total porosity when processed in the temperature range of $400-600{ }^{\circ} \mathrm{C}$. Table 3 shows that the carbon fibers processed to $800^{\circ} \mathrm{C}$ have markedly lower porosity (i.e. pore collapse occurred). 
For all three carbon fibers, micropores (pores with widths of $20 \AA$ or less) represented $20 \%$ of the porosity. Accordingly, the average pore diameters decreased as a function of process temperature. 


\begin{tabular}{cccc} 
Nanofiber & $\begin{array}{c}\text { BET } \\
\text { surface } \\
\text { area } \\
\left(\mathbf{m}^{2} / \mathbf{g}\right)\end{array}$ & $\begin{array}{c}\text { Average } \\
\text { pore } \\
\text { diameter } \\
(\AA)\end{array}$ & $\begin{array}{c}\text { Total Pore } \\
\text { Volume }^{1}\left(\mathbf{c m}^{3} / \mathbf{g}\right)\end{array}$ \\
\hline SU-8 & 9.75 & 79 & 0.0095 \\
$400^{\circ} \mathrm{C}$ & 38.0 & 140 & 0.156 \\
$600^{\circ} \mathrm{C}$ & 278 & 55 & 0.195 \\
$800^{\circ} \mathrm{C}$ & 352 & $<20$ & 0.057
\end{tabular}

1. Calculated using BJH porosity model

Table 3. Surface area and pore structure of electrospun nanofibers 


\subsection{Extraction and Analysis of BTEX}

The extraction capability of the electrospun nanofiber coated SPME fibers was first examined via the extraction of benzene, toluene, ethylbenzene, and oxylene (BTEX). BTEX compounds were chosen as the first investigated analytes, as they are common contaminants of groundwater and soil, originating from petroleum products. Accordingly, the extraction of these compounds has been extensively studied. ${ }^{37,38,39}$ Figure 9 shows the quantity extracted as a function of time for 40 ppm solutions of individual BTEX compounds by the SU-8 fiber-coated wire. This nanofiber-coated wire was not pyrolyzed but only conditioned in the inlet at a temperature of $300^{\circ} \mathrm{C}$. The results indicate that the equilibration time for headspace extraction of BTEX for the SU-8 fiber-coated wire was approximately 60 minutes for all four BTEX compounds.

For the pyrolyzed fiber-coated wires of 400,600 , and $800^{\circ} \mathrm{C}$, the extraction time profiles were also investigated. Figure 10 shows a representative extraction time profile for BTEX using a fiber that was processed to $400^{\circ} \mathrm{C}$. Extraction time profiles for fibers processed to 600 and $800^{\circ} \mathrm{C}$ are shown in Figures 11 and 12, respectively. Observed equilibration for the compounds was also approximately 60 minutes. When comparing the total amount extracted for the BTEX compounds as a function of the processing temperature, the fibers processed to $600^{\circ} \mathrm{C}$ provided the highest extraction efficiency. Figures $9-12$ also clearly illustrate that the selectivity of the SU-8 and carbon fibers differs. 


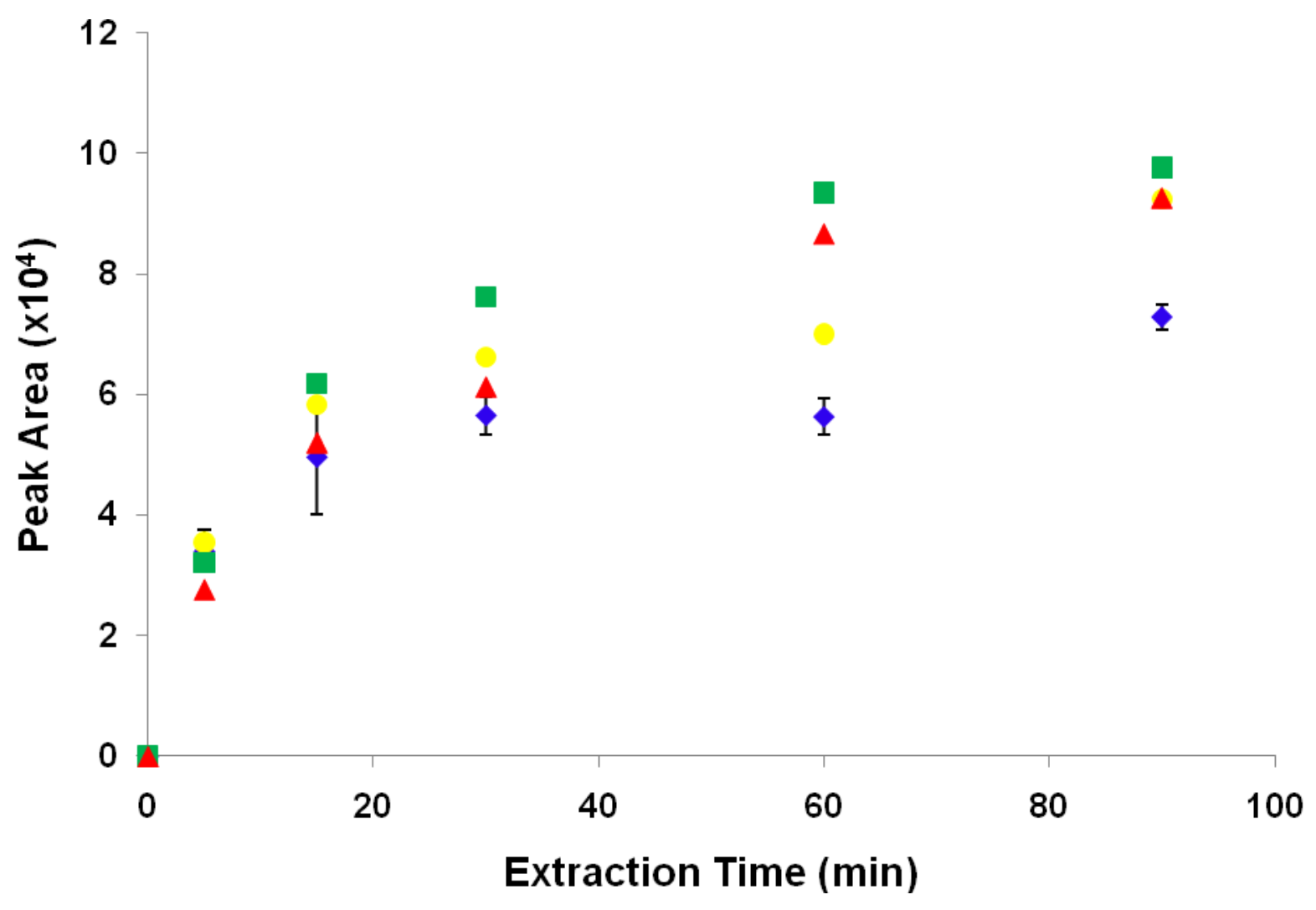

Figure 9. Extraction time profile for the analysis of $40 \mathrm{ppm}$ BTEX, benzene ( $\diamond)$, toluene $(\bullet)$, ethylbenzene $(\square)$, and o-xylene $(\boldsymbol{\Delta})$, with an SU-8 electrospun fiber-coated SPME wire. GC conditions for nonpolar analytes: $30^{\circ} \mathrm{C}$ for $1 \mathrm{~min}$, then programmed at $5^{\circ} \mathrm{C} / \mathrm{min}$ to $180^{\circ} \mathrm{C}$; inlet temperature set at $280^{\circ} \mathrm{C}$ and detector temperature set at $300^{\circ} \mathrm{C}$. Error was of the same magnitude for all analytes. 


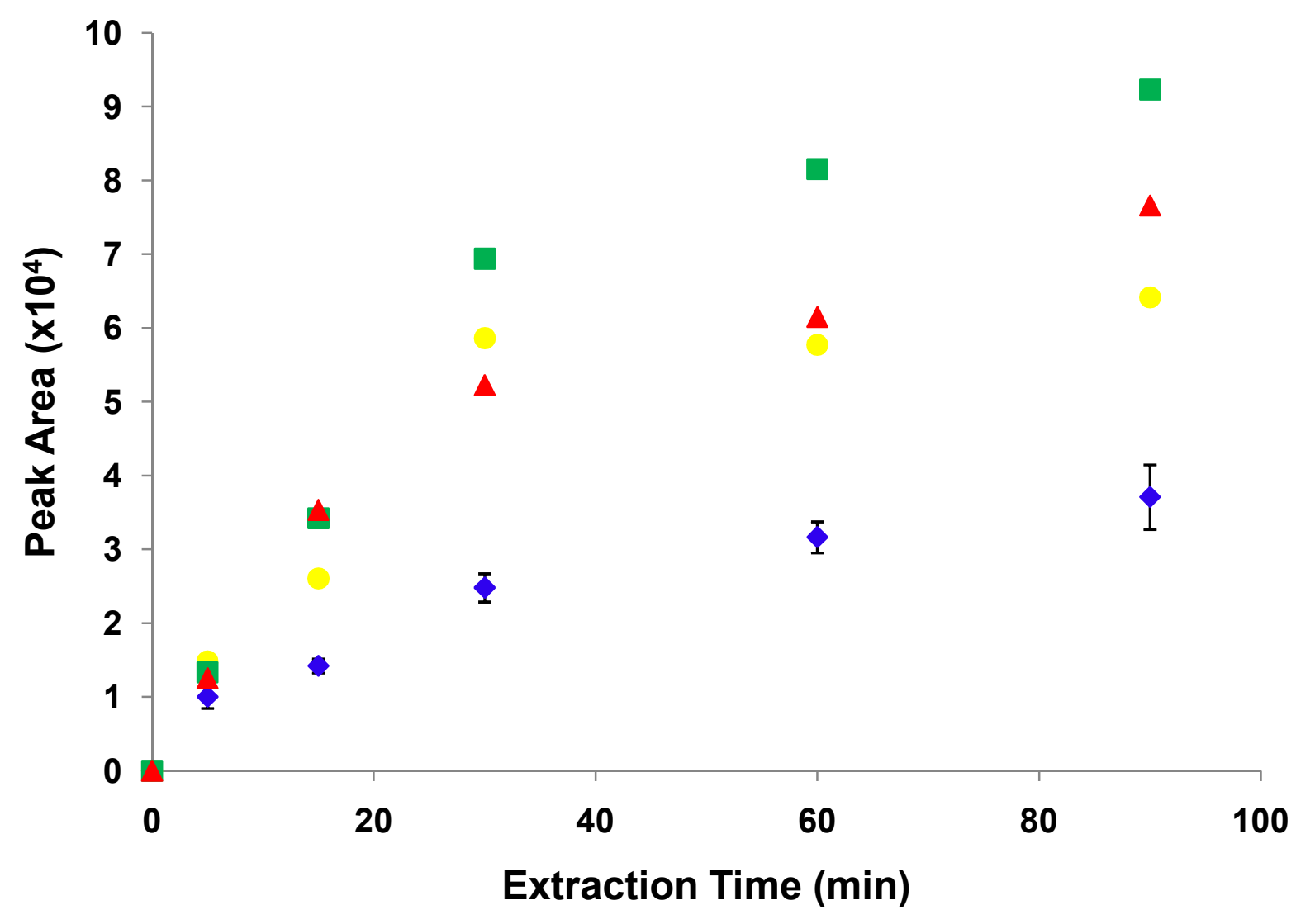

Figure 10. Extraction time profile for the analysis of $40 \mathrm{ppm}$ BTEX, benzene ( $\bullet)$, toluene ( ), ethylbenzene $(\square)$, and o-xylene $(\Delta)$, with a $400^{\circ} \mathrm{C}$ electrospun fiber-coated SPME wire. Error was of the same magnitude for all analytes. 


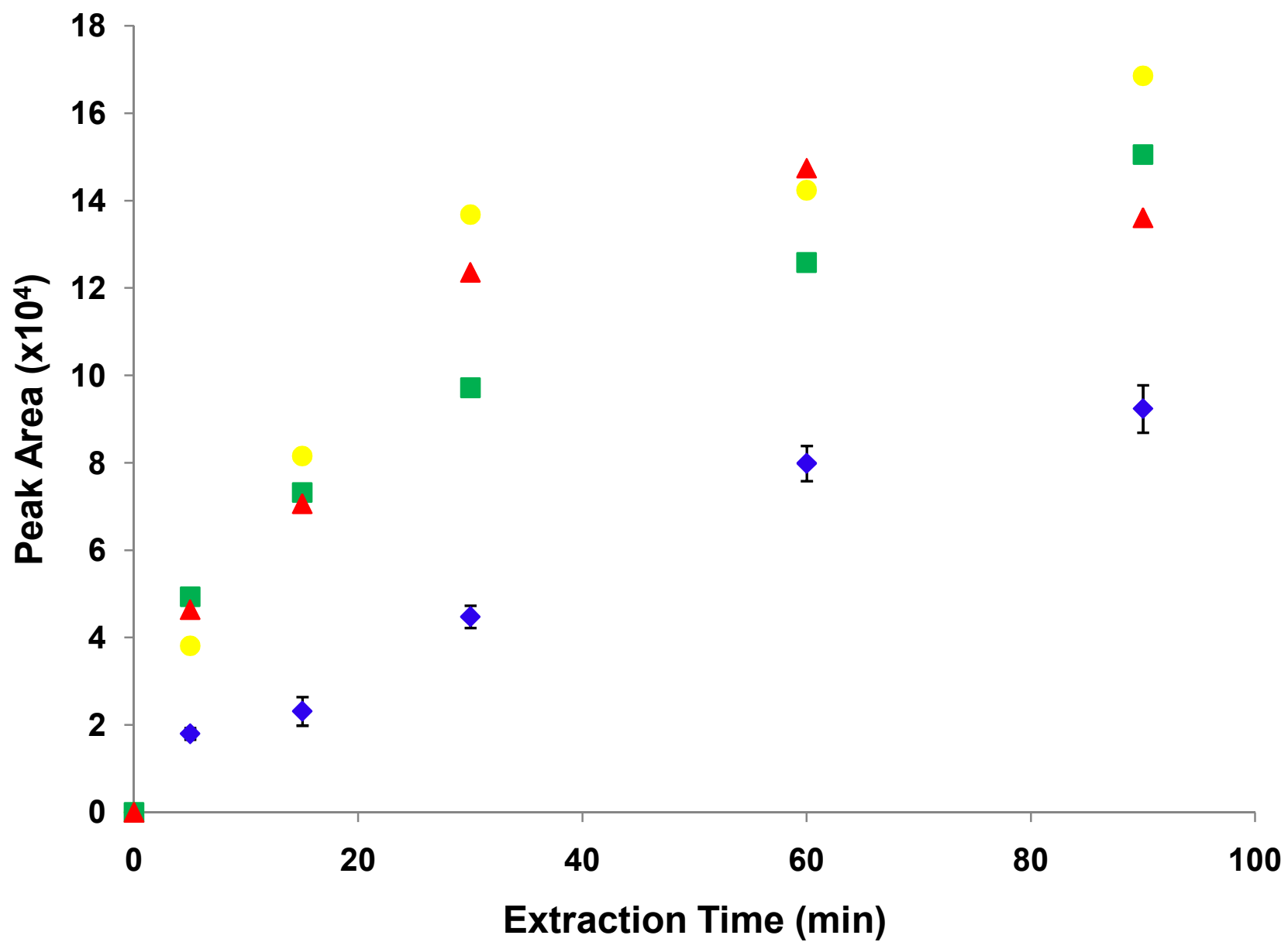

Figure 11. Extraction time profile for the analysis of BTEX, benzene ( $\bullet)$, toluene ( ), ethylbenzene $(\square)$, and o-xylene $(\Delta)$, with a $600^{\circ} \mathrm{C}$ electrospun fiber-coated SPME wire. Error was of the same magnitude for all analytes. 


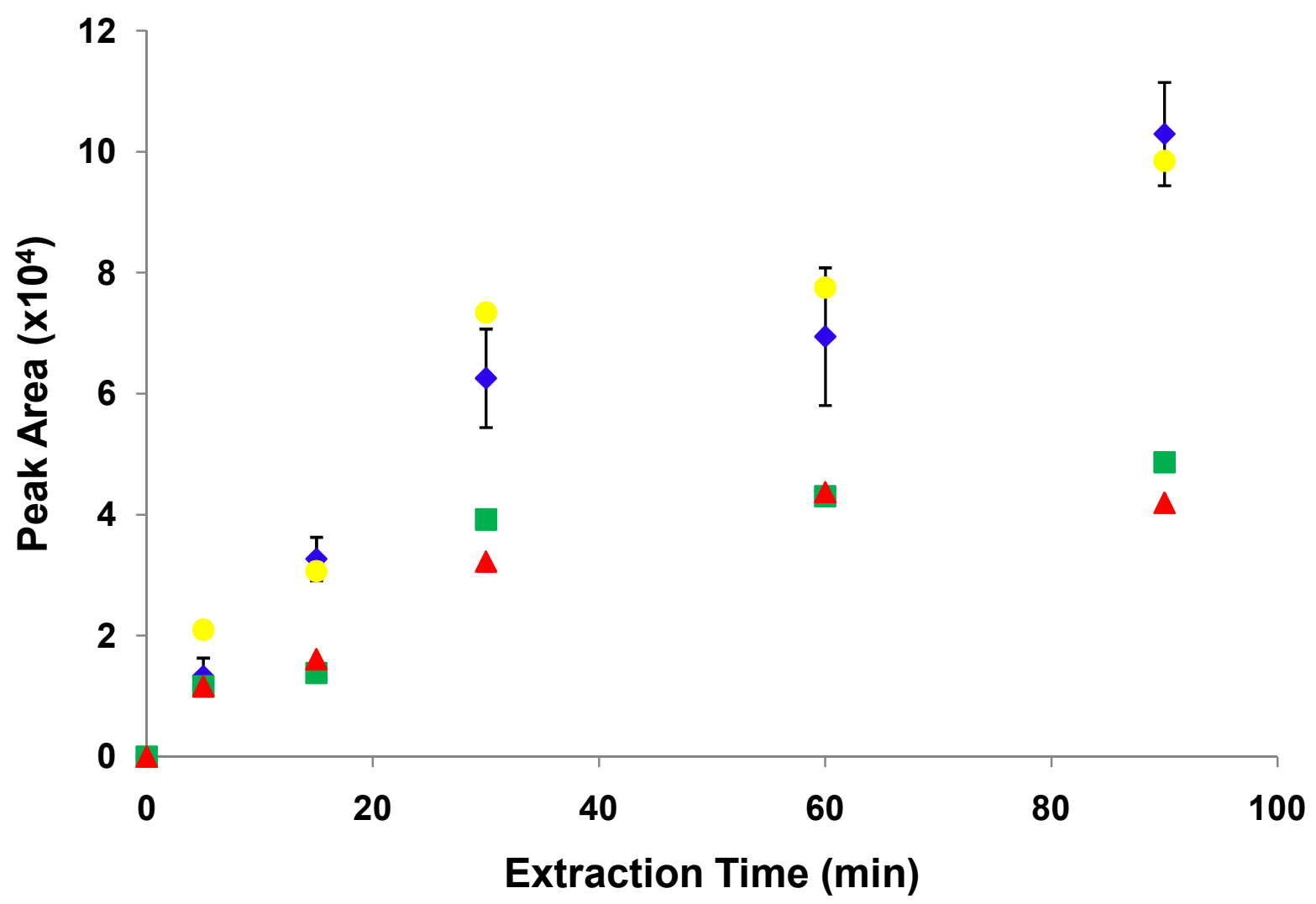

Figure 12. Extraction time profile for the analysis of 40 ppm BTEX, benzene ( $\bullet$ ), toluene ( $(\circ)$, ethylbenzene $(\square)$, and o-xylene $(\Delta)$, with a $800^{\circ} \mathrm{C}$ electrospun fiber-coated SPME wire. Error was of the same magnitude for all analytes. 
Possible carryover of an analyte from one extraction to the next was evaluated for fibers processed to each final temperature $\left(400,600\right.$, and $\left.800^{\circ} \mathrm{C}\right)$, as well as the SU-8 SPME fibers, following an extraction time of 60 minutes and subsequent desorption. The carryover was found to be well below $0.05 \%$ for all of the BTEX compounds for each of the SPME fibers except the fiber processed to $800^{\circ} \mathrm{C}$ which had measured carryover amounts less than $0.2 \%$ for all compounds.

The extraction performance of the electrospun-fiber coated wires was compared to that of commercial fibers of PDMS and PDMS/DVB using the extraction conditions described in section 2. Figures 13-16 show the comparison of extraction efficiency of the BTEX compounds per unit coating thickness for the studied fibers. The electrospun fibers performed as good as, or better than, the commercially-available fibers. Enhanced extraction efficiencies/coating thickness were observed for benzene and toluene using the 600 and $800{ }^{\circ} \mathrm{C}$ fibers, and for ethylbenzene using the $600^{\circ} \mathrm{C}$ fiber. The extraction efficiency/coating thickness for o-xylene using the $600^{\circ} \mathrm{C}$ fiber was comparable to that of the PDMS/DVB fiber. 


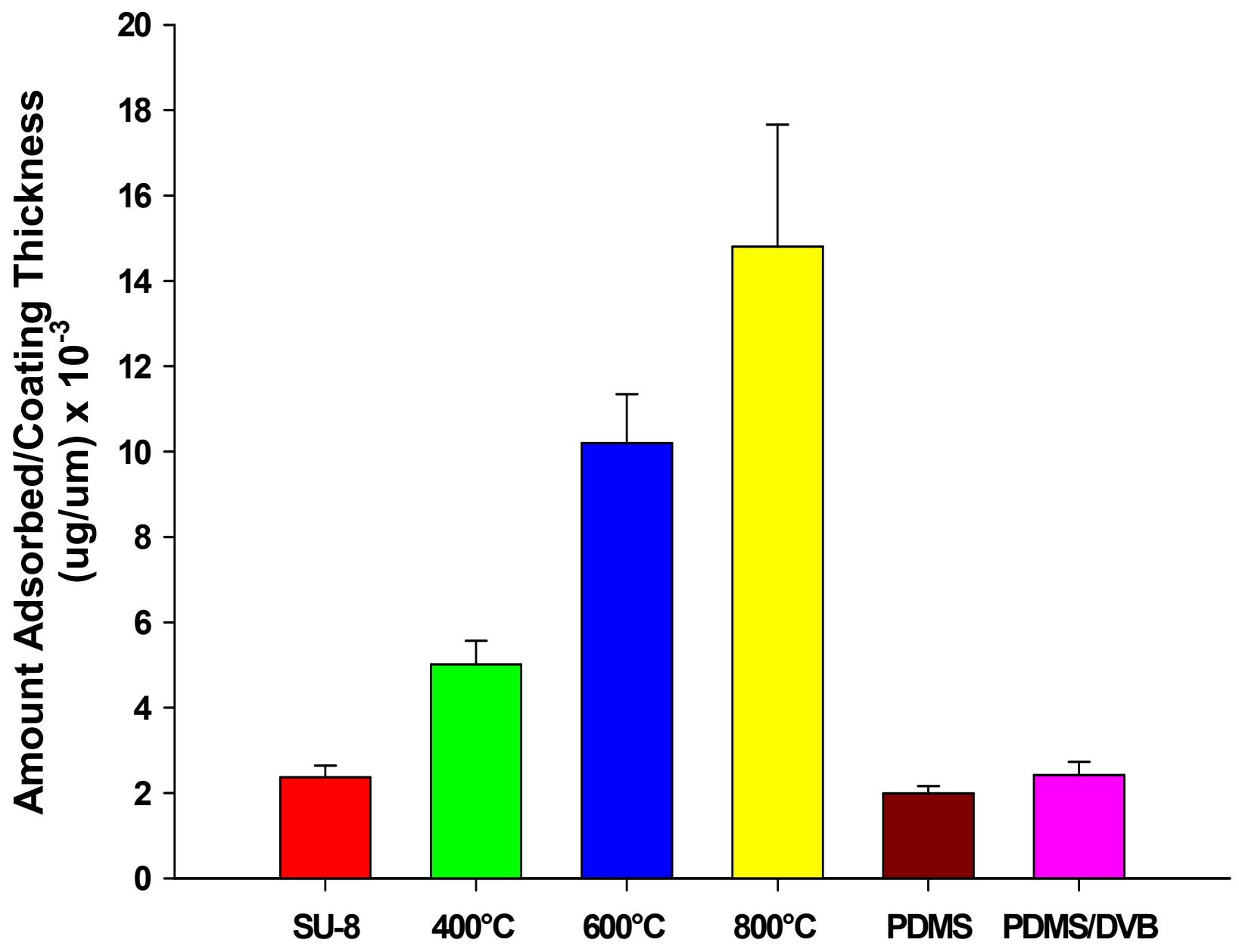

Figure 13. Extraction efficiency of the electrospun fiber-coated SPME wires and the commercial fibers (PDMS and PDMS/DVB) for benzene. 


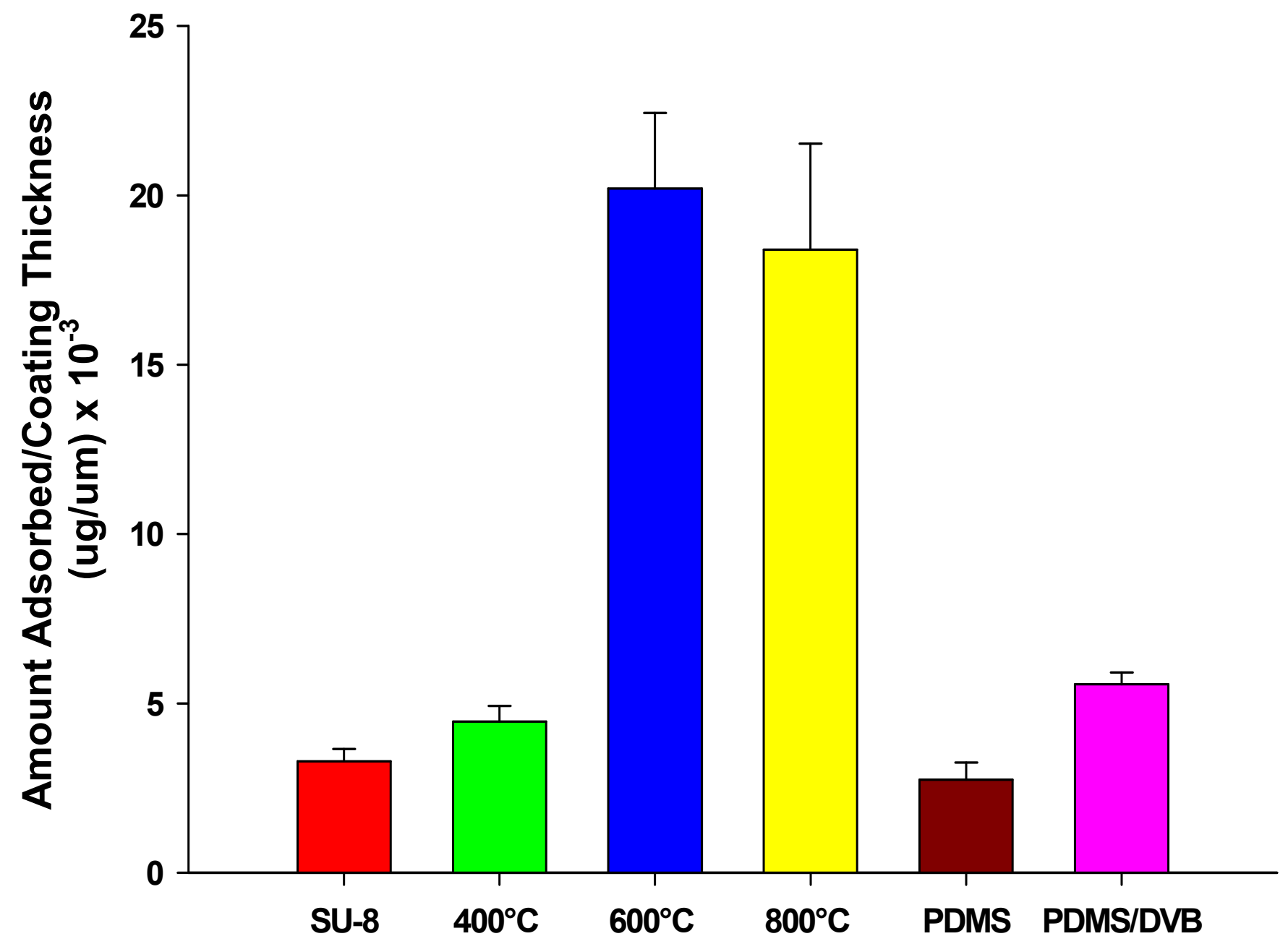

Figure 14. Extraction efficiency of the electrospun fiber-coated SPME wires and the commercial fibers (PDMS and PDMS/DVB) for toluene. 


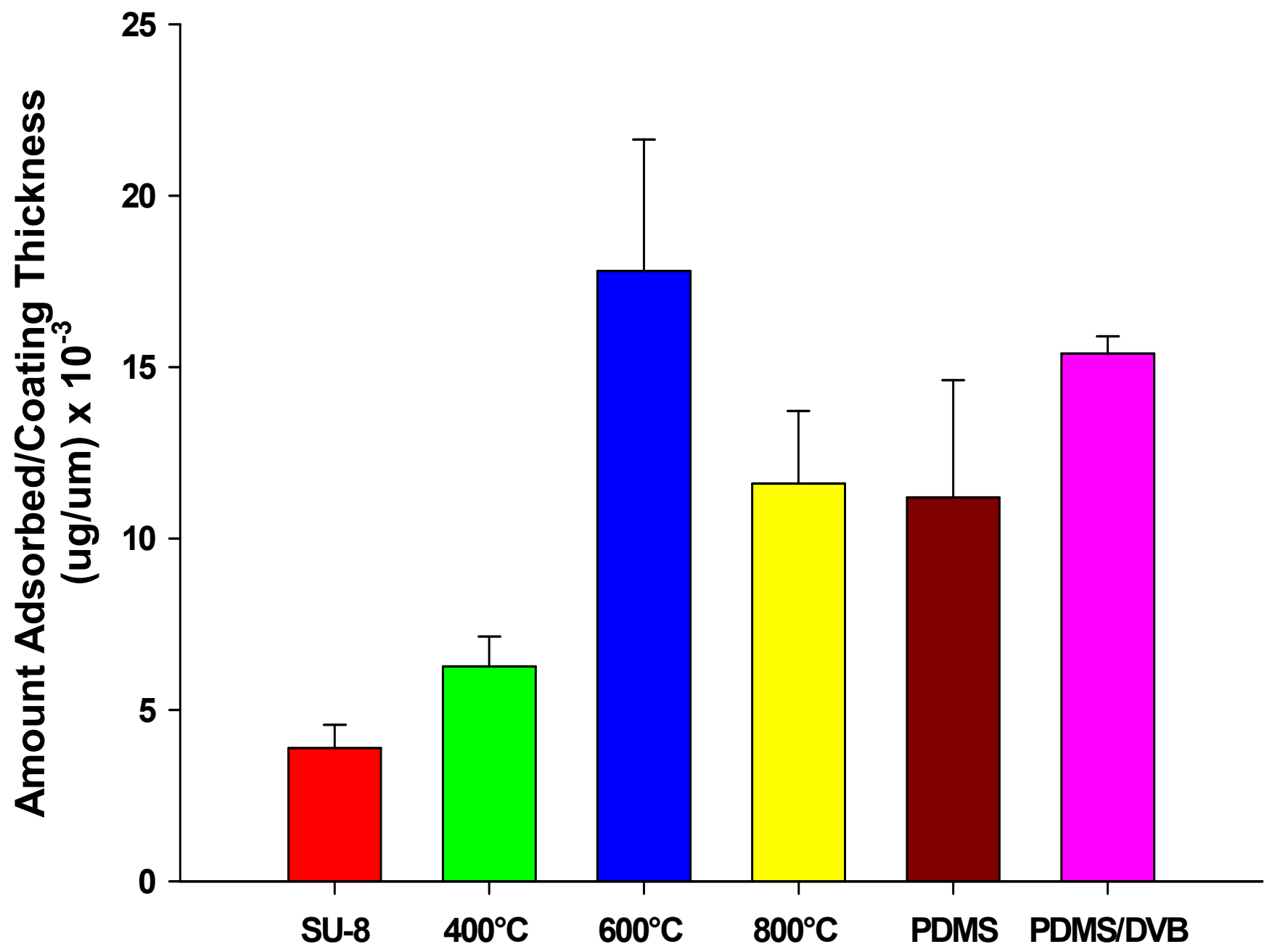

Figure 15. Extraction efficiency of the electrospun fiber-coated SPME wires and the commercial fibers (PDMS and PDMS/DVB) for ethylbenzene. 


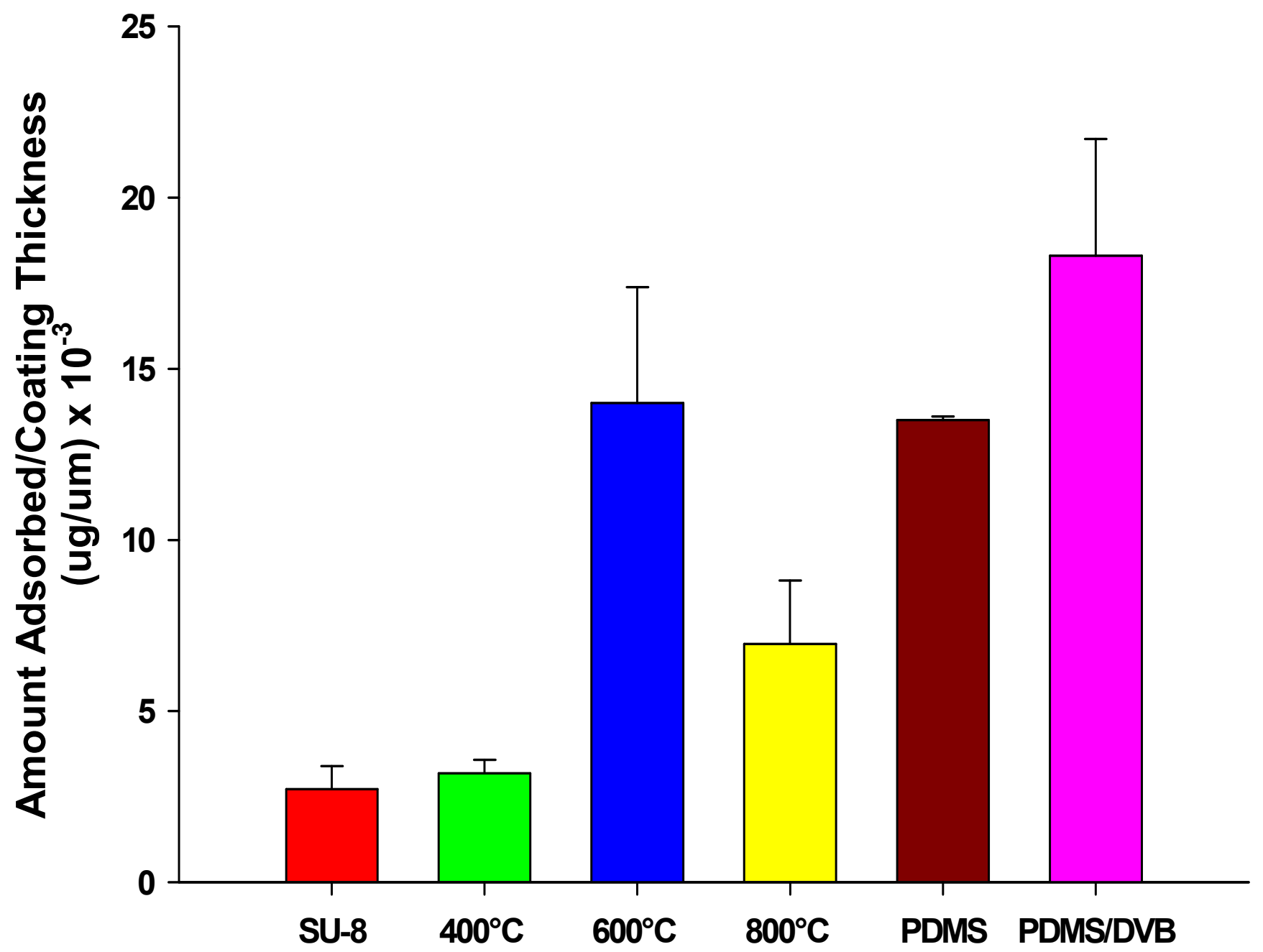

Figure 16. Extraction efficiency of the electrospun fiber-coated SPME wires and the commercial fibers (PDMS and PDMS/DVB) for o-xylene. 
To quantify the extent of the analyte interactions with each processing temperature of the fiber, the distribution coefficient, $K$, was determined for the SU-8, 400,600 , and $800^{\circ} \mathrm{C}$ SPME fibers for the headspace extraction of benzene in an aqueous solution, using equation 4 :

$$
K=\frac{n\left(K_{H} V_{h}+V_{S}\right)}{V_{f}\left(C_{f \max }-C_{f}^{\infty}\right)\left(C_{o} V_{s}-n\right)}
$$

where $C_{0}$ is the initial concentration of the analyte in the sample solution, $C_{f \max }$ is the maximum concentration of active sites on the fiber coating, $C_{f}^{\infty}$ is the analyte concentration on the fiber at equilibrium, $K_{H}$ is the dimensionless Henry's law constant for the analyte ( 0.25 for benzene), $n$ is the amount of analyte extracted by the fiber at equilibrium, $V_{f}$ is the volume of the phase coating on the fiber, $V_{h}$ is the volume of the headspace, and $V_{s}$ is the volume of the solution. This equation assumes that analyte extraction occurs via adsorption, which, as previously described, is expected for solid fiber coatings. It is identical to the equation presented in section 1.2 for the determination of the distribution constant for solid fibers in the direct extraction mode, except that this equation includes the necessary terms to describe the concentration of the analyte in the headspace and the subsequent equilibrium between the headspace and the fiber coating. ${ }^{7}$

All extractions for the determination of $K$ were carried out in the headspace extraction mode; the extraction procedure described previously for the extraction time profiles was applied. Benzene concentration was varied from 4-40 ppm; the extraction time was 60 minutes. It has been demonstrated that a 
plot of $1 / C_{f}^{\infty}$ versus $1 / C_{s}^{\infty}$, where $C_{s}^{\infty}$ is the analyte concentration in the sample at equilibrium, gives a straight line where the $y$-intercept is equal to $1 / C_{f \max } . C_{f}^{\infty}$ and $C_{s}^{\infty}$ were determined by measuring the concentration of benzene in the sample solution before and immediately after extraction using gas chromatography. ${ }^{7}$ Plots of this type were constructed for each fiber, and are displayed in Figures 17-20. A calibration curve of benzene was performed so that the amount present in solution could be quantified with undecane used as the internal standard. 


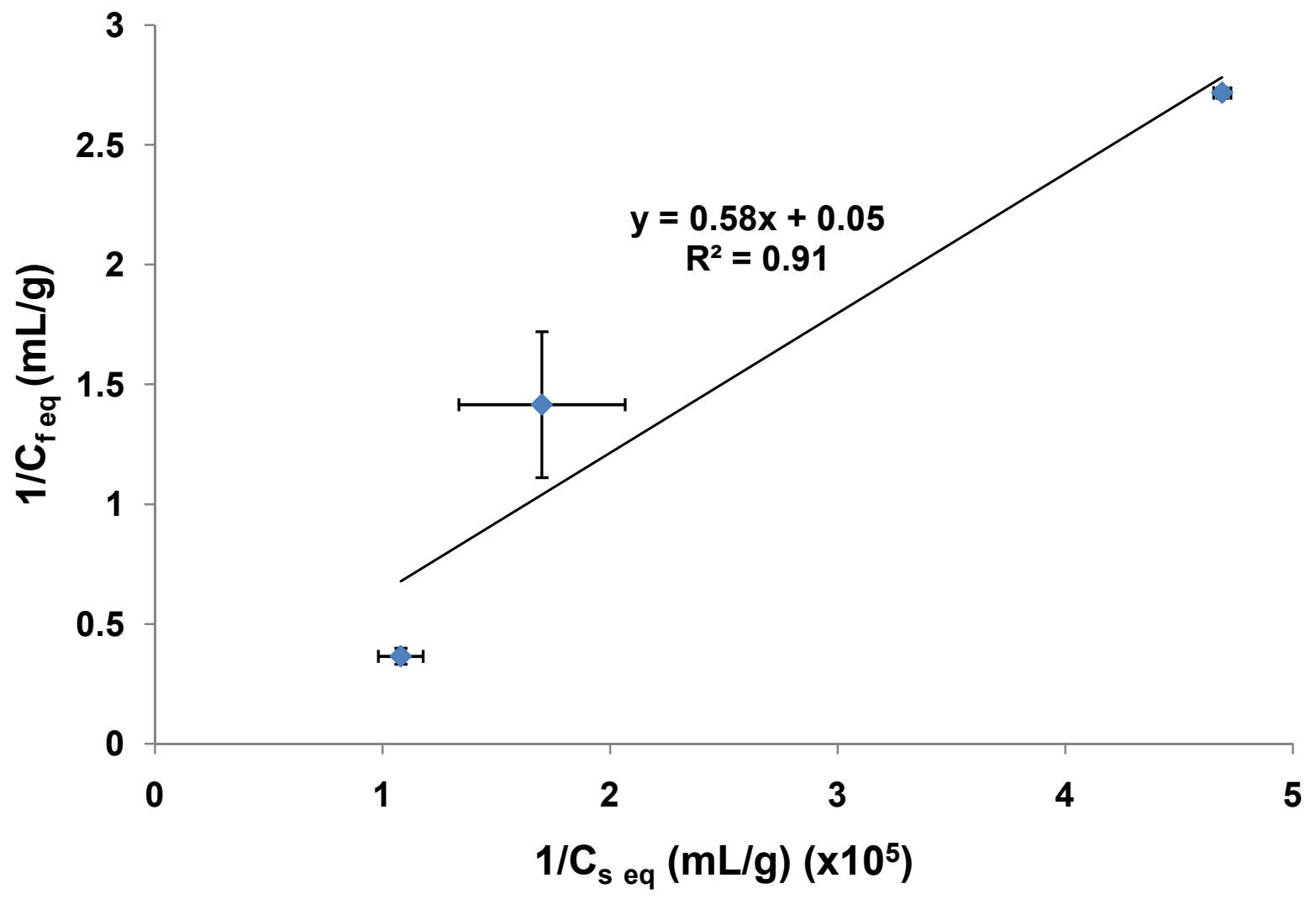

Figure 17. Determination of $1 / C_{f \max }$ for the headspace extraction of benzene with an SU-8 SPME fiber. 


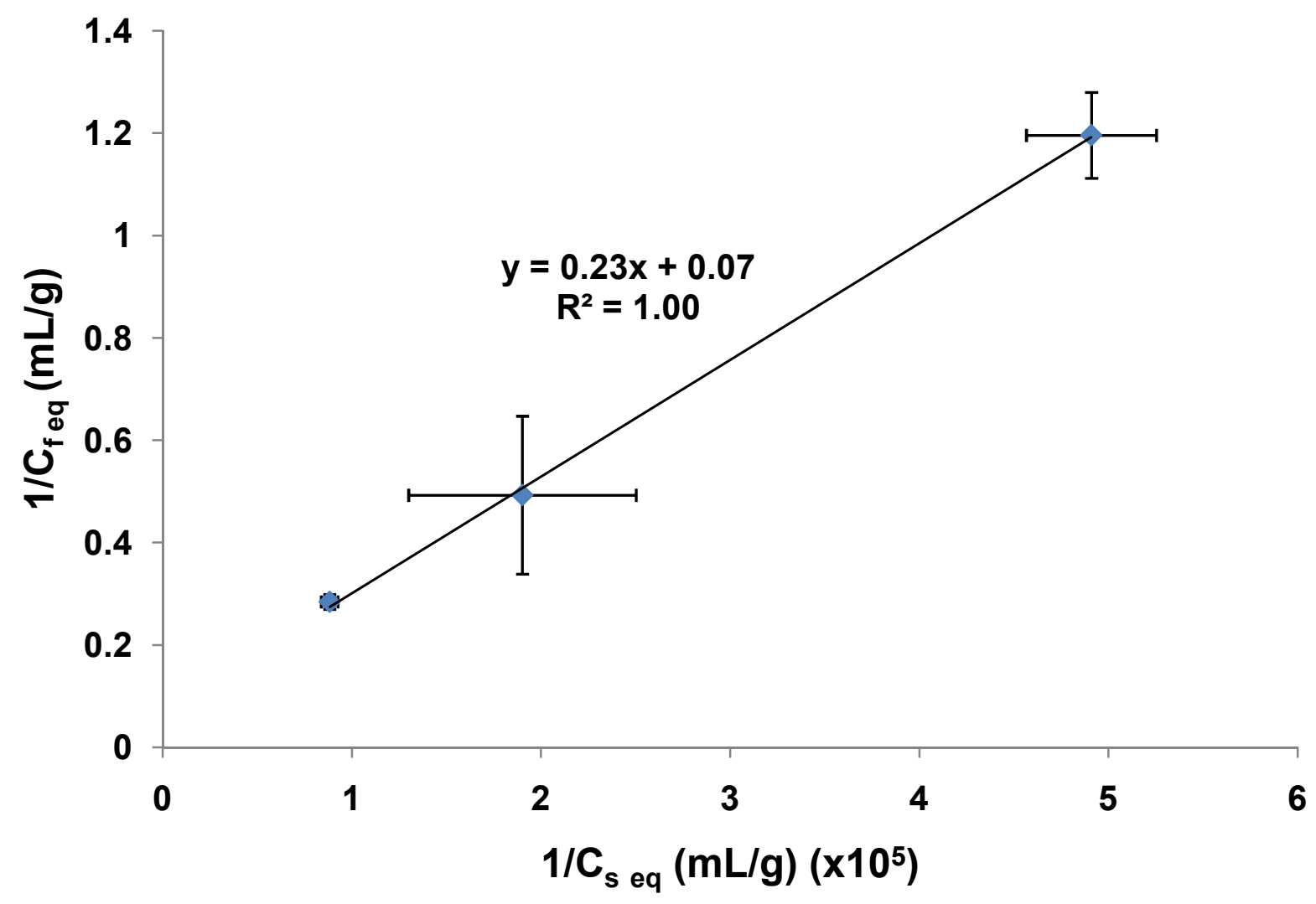

Figure 18. Determination of $1 / C_{f \max }$ for the headspace extraction of benzene with a $400^{\circ} \mathrm{C}$ SPME fiber. 


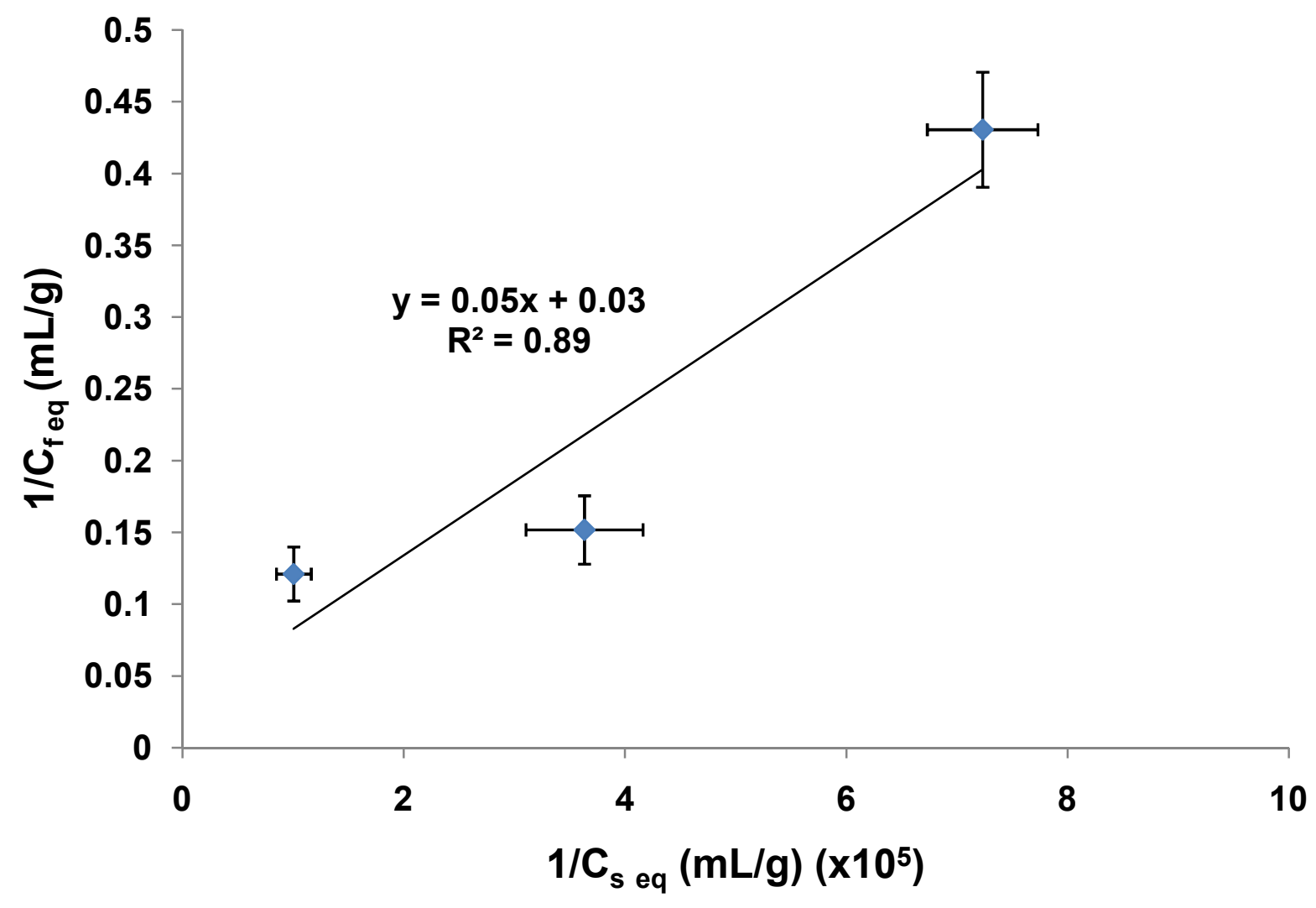

Figure 19. Determination of $1 / C_{f \max }$ for the headspace extraction of benzene with a $600^{\circ} \mathrm{C}$ SPME fiber. 


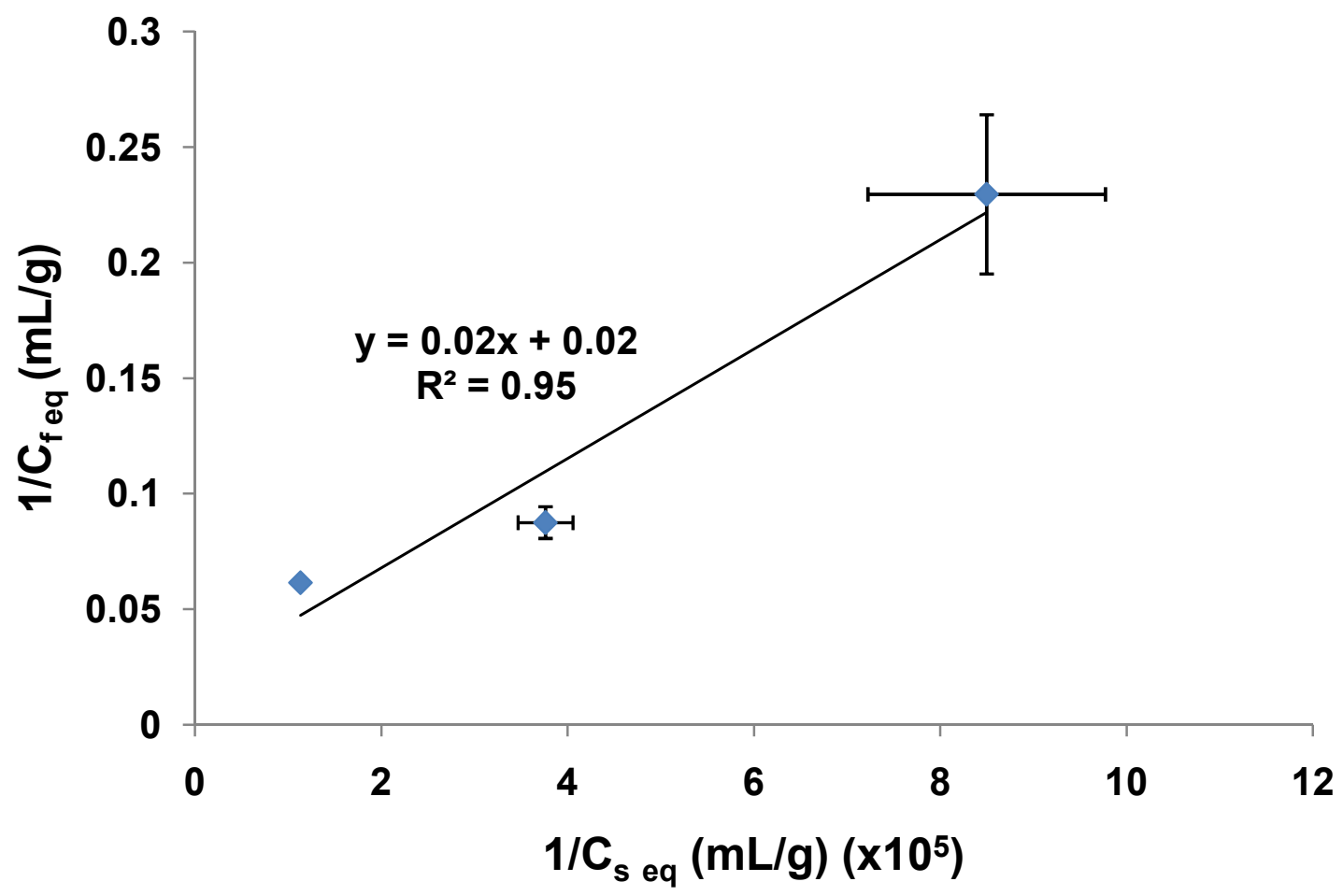

Figure 20. Determination of $1 / C_{f \max }$ for the headspace extraction of benzene with a $800^{\circ} \mathrm{C}$ SPME fiber. 
The distribution coefficients, $K$, for each of the fiber coatings for headspace extraction of benzene from an aqueous matrix, are shown in Table 4 . The distribution coefficient clearly increases with processing temperature. Distribution coefficients for benzene on PDMS and PDMS/DVB fibers under similar head space extraction conditions were previously determined to be $100-$ $200.40,41,42$ 


\section{Fiber Coating}

SU-8 2100
$400^{\circ} \mathrm{C}$
$600^{\circ} \mathrm{C}$
$800^{\circ} \mathrm{C}$

K

240

980

1800

2500

Table 4. Distribution constant, $K$, values for electrospun coated SPME fibers for the headspace extraction of benzene. 
The limit of detection and linear range for 600 and $800^{\circ} \mathrm{C}$ electrospun-fiber coated SPME wires were examined for benzene and ethylbenzene (Table 5). These two fibers were chosen because they both displayed the highest extraction efficiency for benzene and ethylbenzene of the electrospun-fiber coated SPME fibers. The detection limit of benzene determined for both the $600^{\circ} \mathrm{C}$ and $800^{\circ} \mathrm{C}$ fibers was $0.3 \mathrm{ng} / \mathrm{mL}$ and $0.4 \mathrm{ng} / \mathrm{mL}$, respectively. For ethylbenzene the detection limit was $0.9 \mathrm{ng} / \mathrm{mL}$ for the $600^{\circ} \mathrm{C}$ fiber and $1 \mathrm{ng} / \mathrm{mL}$ for the $800^{\circ} \mathrm{C}$ fiber. It is interesting to point out that both of these fibers have a wide linear range $(0.05-40 \mu \mathrm{g} / \mathrm{mL})$ for a small coating thickness. The large linear range can be attributed to the high surface area of the nanofibers. The detection limits for both the 600 and $800^{\circ} \mathrm{C}$ electrospun-fiber coated fibers are comparable to previously published SPME coatings but the linear range of these coated wires was larger than previously reported for these commercially-available SPME fibers. ${ }^{39,41}$ Previously studies on headspace extraction of BTEX using PDMS fibers showed a linear range covering two orders of magnitude and PDMS/DVB fibers have a linear range of $0.01-1 \mu \mathrm{g} / \mathrm{mL} .^{43,44}$ 


\begin{tabular}{|c|c|c|c|c|c|}
\hline Fiber & Compound & $\begin{array}{l}\text { Linear } \\
\text { Range } \\
(\mu \mathrm{g} / \mathrm{mL})\end{array}$ & $\begin{array}{l}\text { Limit of } \\
\text { Detection } \\
(\mathrm{ng} / \mathrm{mL})^{\mathrm{a}}\end{array}$ & $\begin{array}{l}\text { Correlation } \\
\text { Coefficient }\end{array}$ & $\begin{array}{c}\text { Relative } \\
\text { Standard } \\
\text { Deviation } \\
(\%)\end{array}$ \\
\hline \multirow[t]{2}{*}{$600^{\circ} \mathrm{C}$} & Benzene & $0.05-40$ & 0.3 & 0.92 & 9.7 \\
\hline & Ethylbenzene & $0.05-40$ & 0.9 & 0.98 & 6.4 \\
\hline \multirow[t]{2}{*}{$800^{\circ} \mathrm{C}$} & Benzene & $0.05-40$ & 0.4 & 0.91 & 20 \\
\hline & Ethylbenzene & $0.05-40$ & 1.0 & 0.89 & 17 \\
\hline
\end{tabular}

Table 5. Limits of detection, linear range, and correlation coefficients for the analysis of benzene and ethylbenzene using both 600 and $800^{\circ} \mathrm{C}$ electrospun fiber-coated SPME wires. ( ${ }^{a} \mathrm{k}=3$ for limit of detection calculation) 


\subsection{Extraction and Analysis of Phenolic Compounds}

The determination of phenol and its derivatives is important due to the toxicity of these compounds and their widespread use in various industrial processes, such as the production of Bakelite resin. These compounds have a high polarity and the commercial fibers that are typically used to extract these analytes are polyacrylate and Carbowax/polyethylene glycol fibers. ${ }^{37}$ The concentration of phenolic compounds can be difficult to determine by direct extraction from the matrix with SPME fibers. This type of extraction is difficult because the SPME coating typically is coated by the matrix (usually $\mathrm{H}_{2} \mathrm{O}$ ) which acts as interference with the extraction. ${ }^{45}$ To avoid this type of problem, a headspace extraction above the liquid was employed. Since a headspace extraction was used, the importance of the transfer of the analytes from the aqueous phase to the gas phase was critical. The transfer step can be a challenge for phenolic compounds due to their low Henry's law constant values. It has been previously shown that phenols can be forced into the headspace by decreasing their solubility in the aqueous phase by saturating with sodium chloride and acidifying to below $\mathrm{pH} 1$ with a few drops of concentrated acid. ${ }^{45,46}$

The extraction time profiles for the SU-8, $400^{\circ} \mathrm{C}, 600^{\circ} \mathrm{C}$, and $800^{\circ} \mathrm{C}$ electrospun-fiber coated wires were examined from 0 to 90 minutes for a $0.4 \mathrm{ppm}$ aqueous solution of the aforementioned phenolic compounds under the conditions described in section 2. Figures 21-24 show the profiles for the SU-8 fiber and the three carbon fibers. Equilibrium was reached for all three of the 
phenolic compounds with the SPME fibers in 60 minutes for all of the processing temperatures. Typically, phenol had the longest equilibration time; however it was extracted in a higher proportion by all of the fibers relative to 4-nitrophenol and 4-chlorophenol. 


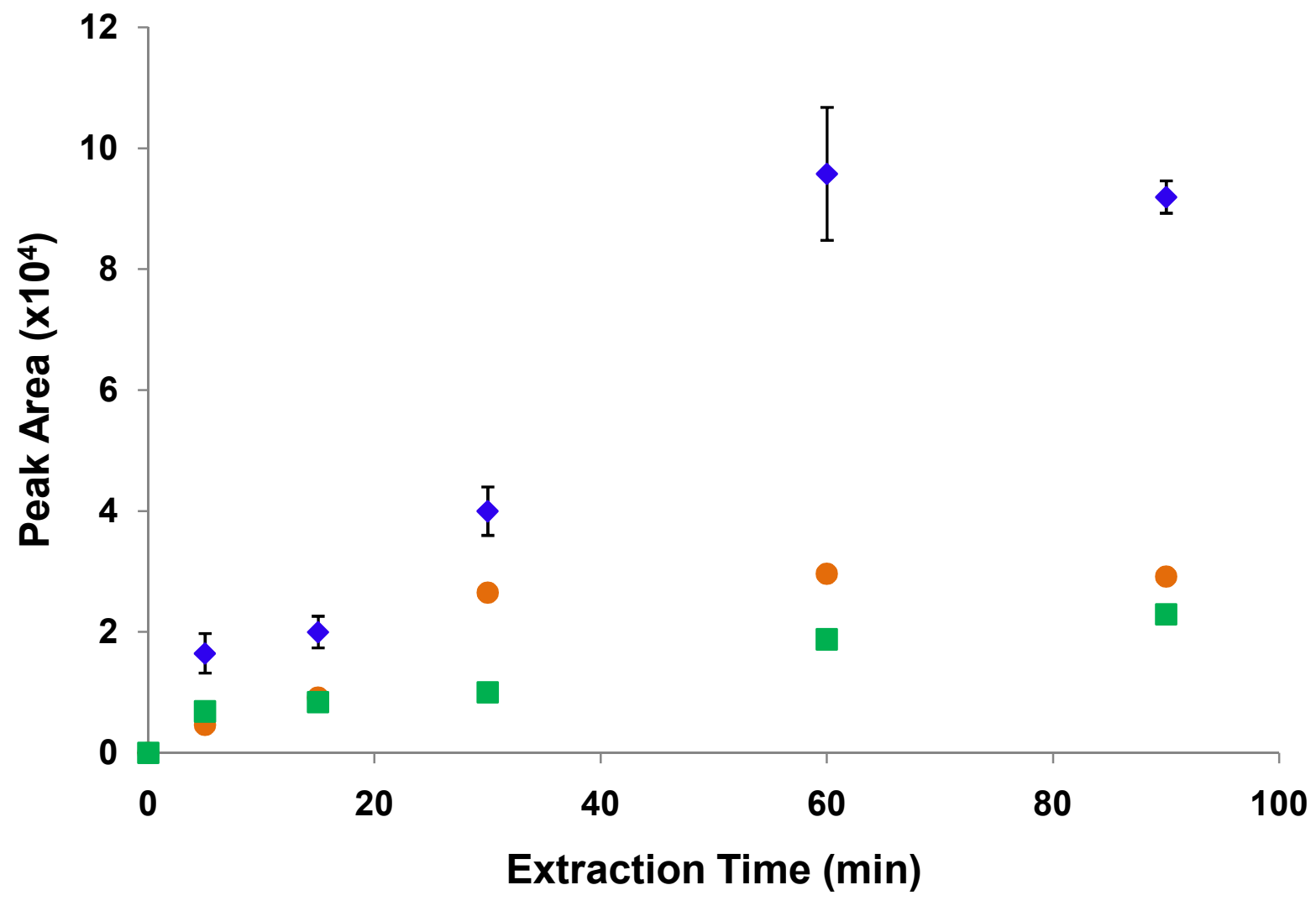

Figure 21. Extraction time profile for the analysis of phenol ( $\downarrow), 4$-chlorophenol $(\square)$, and 4-nitrophenol ( $\bullet$ ) with a SU-8 electrospun fiber-coated SPME wire. GC conditions for polar analytes: $80^{\circ} \mathrm{C}$ for 1 minute then programmed at $10^{\circ} \mathrm{C} / \mathrm{min}$ to $260^{\circ} \mathrm{C}$; inlet temperature set at $320^{\circ} \mathrm{C}$ and detector temperature set at $320^{\circ} \mathrm{C}$. Error was of the same magnitude for all analytes. 


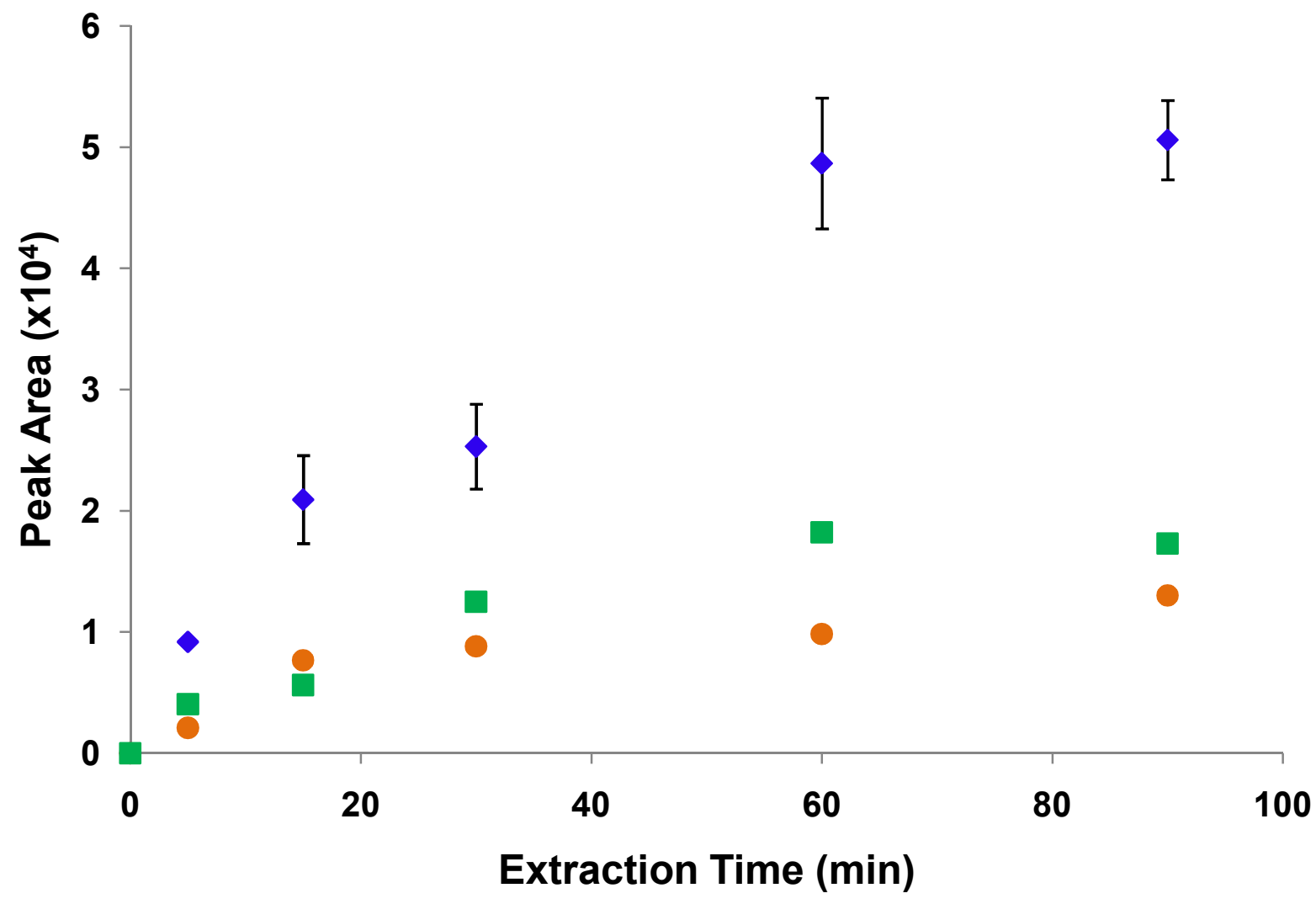

Figure 22. Extraction time profile for the analysis of phenol ( $\diamond), 4$-chlorophenol $(\square)$, and 4-nitrophenol $(\bullet)$ with a $400^{\circ} \mathrm{C}$ electrospun fiber-coated SPME wire Error was of the same magnitude for all analytes. 


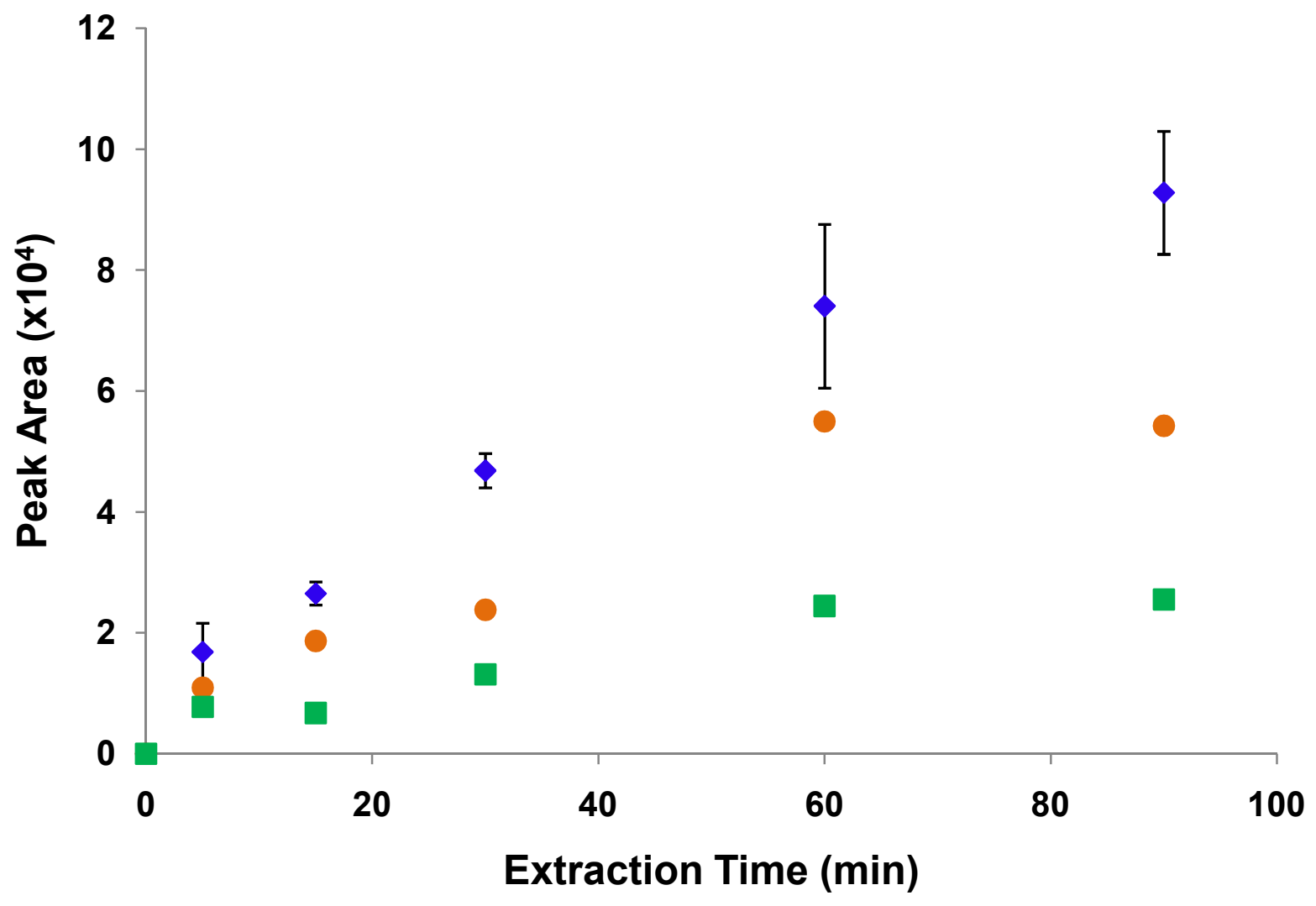

Figure 23. Extraction time profile for the analysis of phenol ( $\downarrow), 4$-chlorophenol $(\square)$, and 4-nitrophenol $(\bullet)$ with a $600^{\circ} \mathrm{C}$ electrospun fiber-coated SPME wire. Error was of the same magnitude for all analytes. 


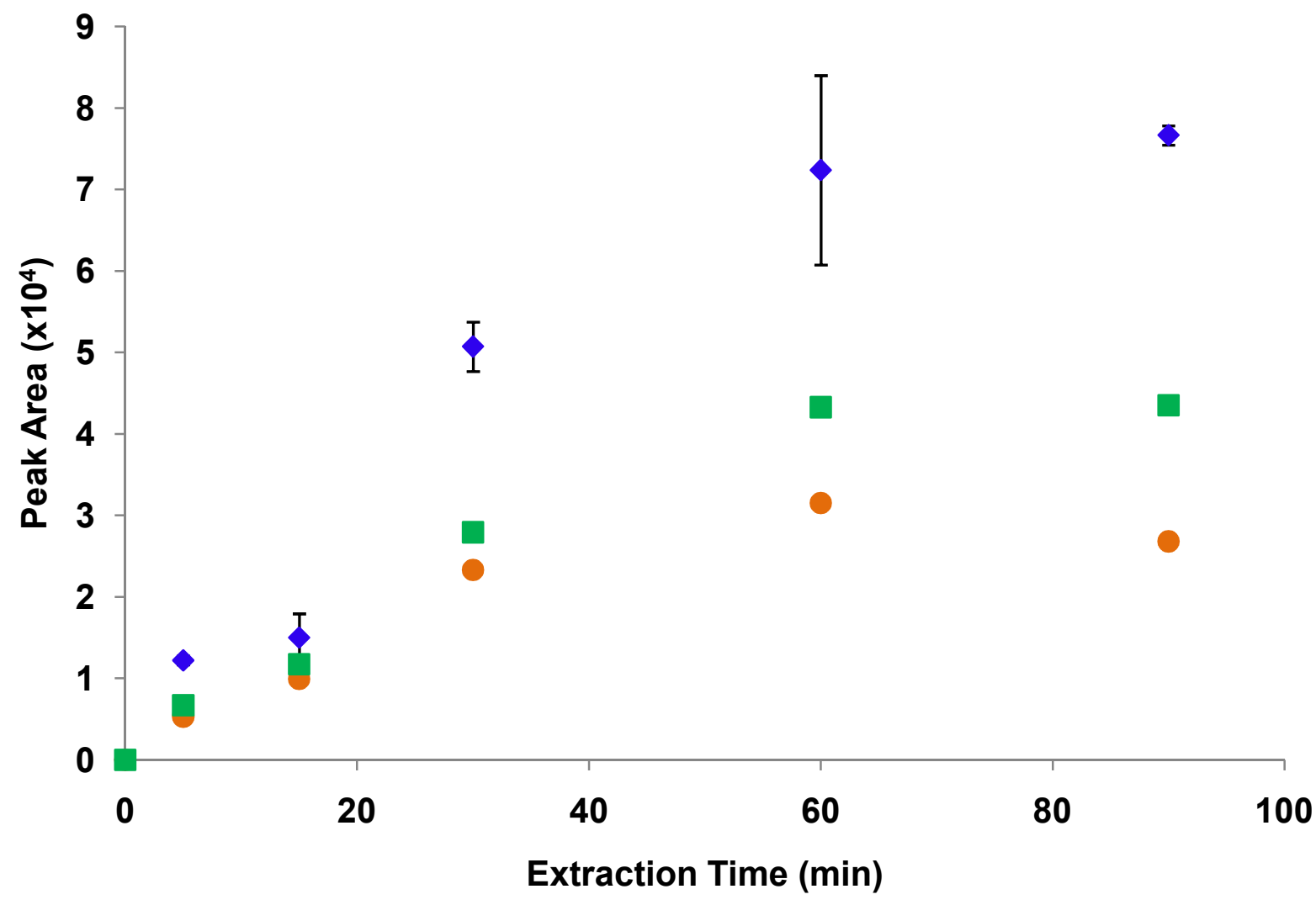

Figure 24. Extraction time profile for the analysis of phenol ( $\diamond), 4$-chlorophenol $(\square)$, and 4-nitrophenol $(\bullet)$ with an $800^{\circ} \mathrm{C}$ electrospun fiber-coated SPME wire. Error was of the same magnitude for all analytes. 
The extraction performance of the four electrospun-fiber coated SPME wires was evaluated and compared to a commercial polyacrylate (PA) SPME fiber. Figure 25 shows that the extraction performance of the $600^{\circ} \mathrm{C}$ and $800^{\circ} \mathrm{C}$ electrospun fibers was better than the PA fiber for phenol. For 4-chlorophenol, the extraction performance of the $800^{\circ} \mathrm{C}$ electrospun fiber was better than the PA fiber while the $600^{\circ} \mathrm{C}$ fiber had comparable extraction efficiency per unit volume (Figure 26). For 4-nitrophenol, the SU-8 SPME fiber had performance comparable to that of the PA fiber while the $600^{\circ} \mathrm{C}$ and $800^{\circ} \mathrm{C}$ electrospun fibers outperformed the commercial fiber (Figure 27). 


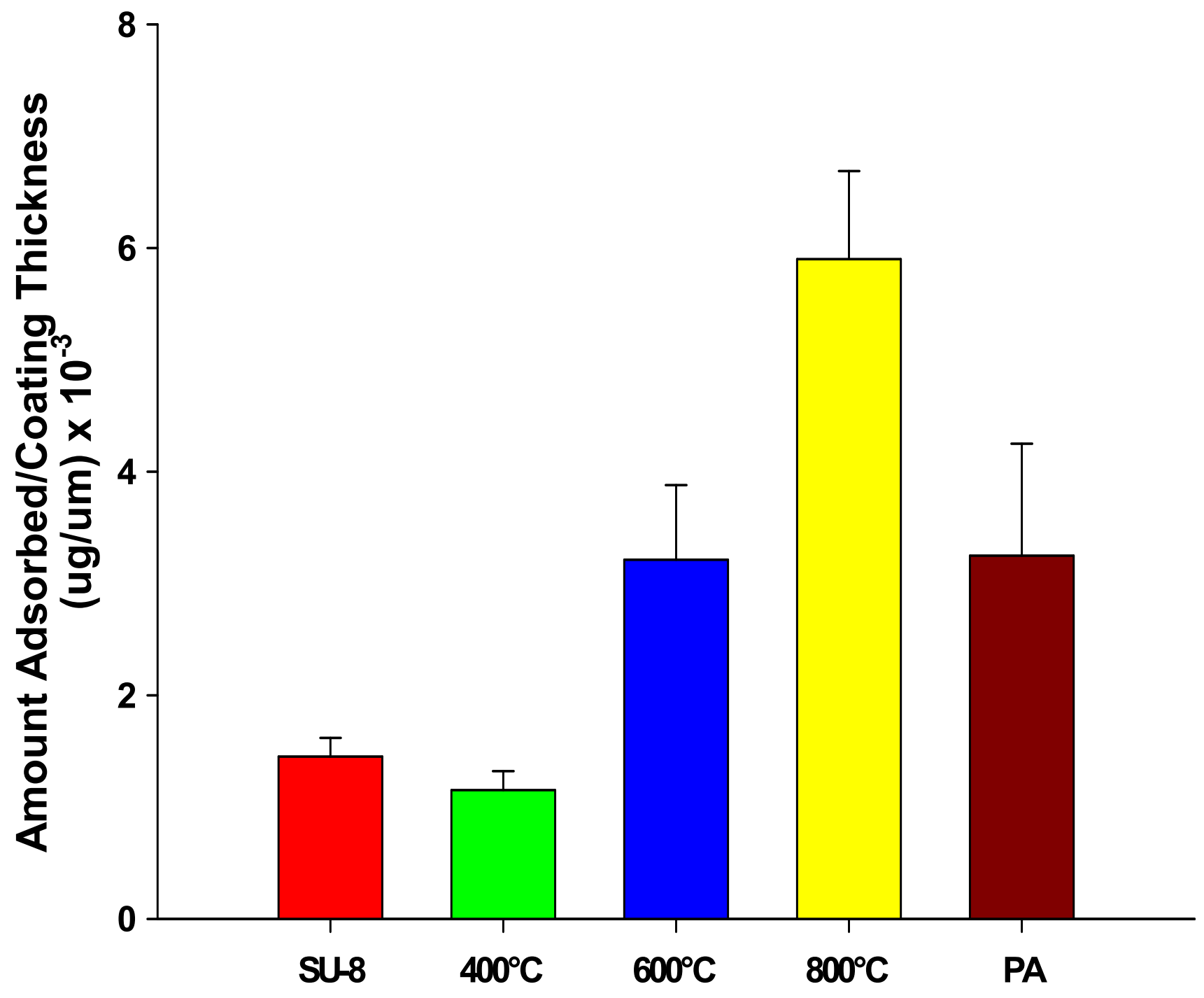

Figure 25. Extraction efficiency of phenol for SU-8, 400, 600, and $800^{\circ} \mathrm{C}$ electrospun fibercoated SPME wires compared to a commercial polyacrylate (PA) fiber. 


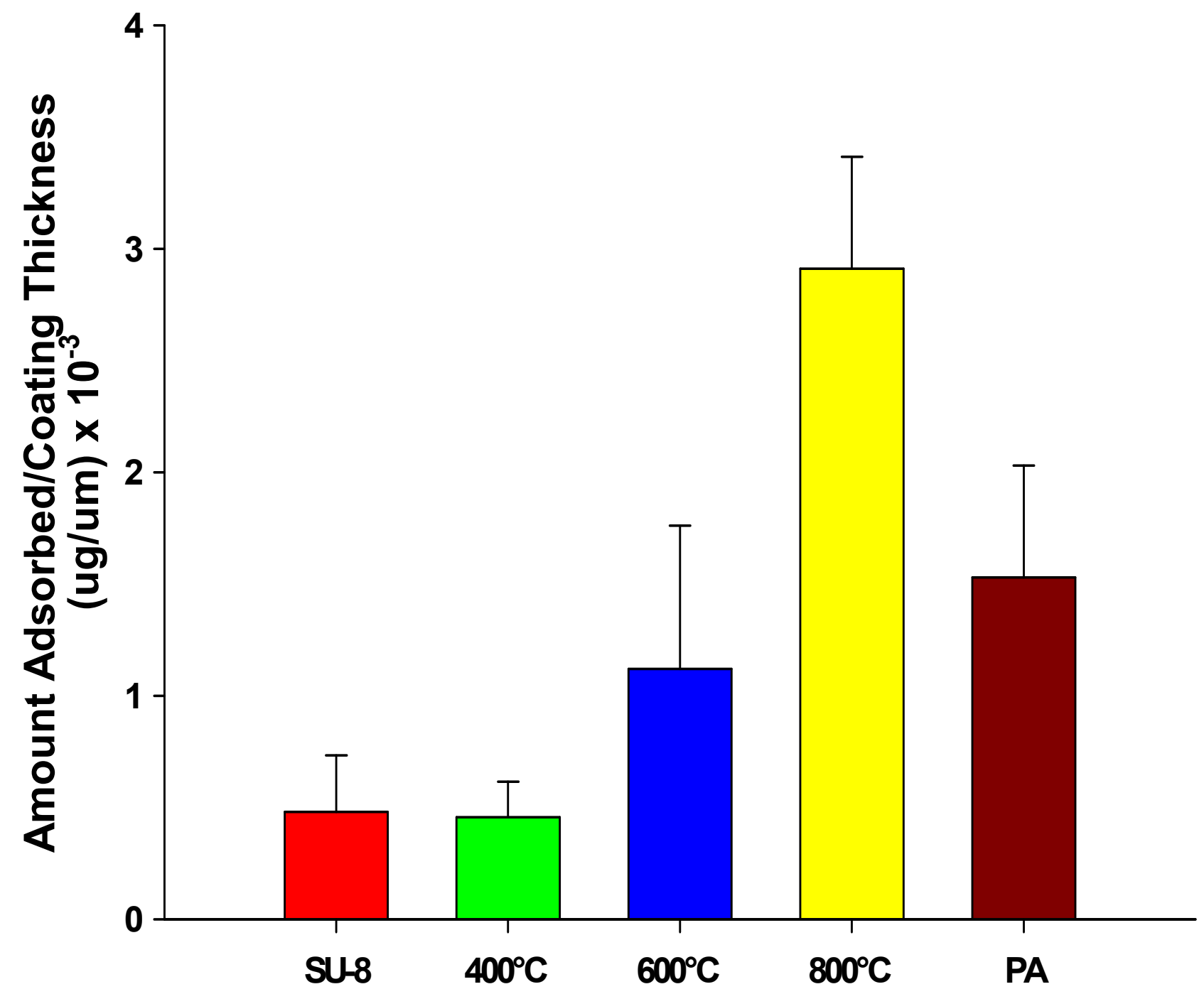

Figure 26. Extraction efficiency of 4-chlorophenol for SU-8, 400, 600, and $800^{\circ} \mathrm{C}$ electrospun fiber-coated SPME wires compared to a commercial polyacrylate (PA) fiber. 


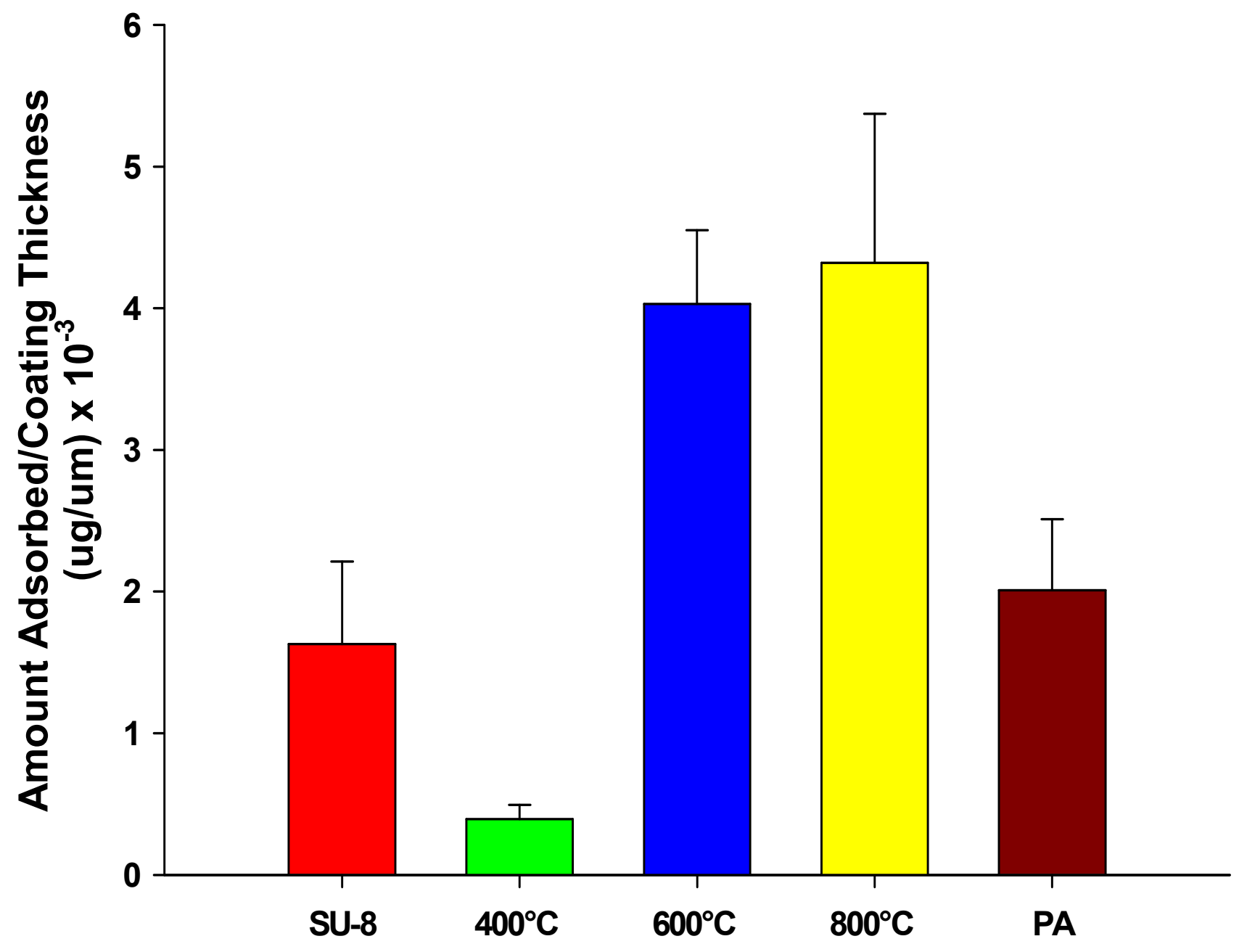

Figure 27. Extraction efficiency of 4-nitrophenol for SU-8, 400, 600, and $800^{\circ} \mathrm{C}$ electrospun fiber-coated SPME wires compared to a commercial polyacrylate (PA) fiber. 
Since the $600^{\circ} \mathrm{C}$ and $800^{\circ} \mathrm{C}$ electrospun fiber coated wires displayed comparable or enhanced extraction efficiencies for all the phenolic compounds in comparison to the PA fiber, these carbon fibers were analyzed for limit of detection and linear range for phenol, 4-chlorophenol, and 4-nitrophenol (Table 6). For the $600^{\circ} \mathrm{C}$ fiber, the limits of detection were found to be $0.01,0.1$, and $0.03 \mathrm{ng} / \mathrm{mL}$ for phenol, 4-chlorophenol, and 4-nitrophenol, respectively. Additionally, the linear range for the $600^{\circ} \mathrm{C}$ fiber was $0.001-1 \mu \mathrm{g} / \mathrm{mL}$ for phenol, 0.001-1 $\mu \mathrm{g} / \mathrm{mL}$ for 4-chlorophenol, and 0.001-0.4 $\mu \mathrm{g} / \mathrm{mL}$ for 4-nitrophenol. For the $800^{\circ} \mathrm{C}$ fiber, the limit of detection was determined to be $0.02 \mathrm{ng} / \mathrm{mL}$ for phenol, $0.08 \mathrm{ng} / \mathrm{mL}$ for 4 -chlorophenol, and $0.04 \mathrm{ng} / \mathrm{mL}$ for 4-nitrophenol. The $800^{\circ} \mathrm{C}$ fiber demonstrated a linear range of $0.001-4 \mu \mathrm{g} / \mathrm{mL}$ for phenol, $0.001-0.4 \mu \mathrm{g} / \mathrm{mL}$ for 4-chlorophenol, and 0.001-4 $\mu \mathrm{g} / \mathrm{mL}$ for 4-nitrophenol. The detection limits obtained for these fibers were comparable to previously published detection limits for other SPME fibers and were lower than those reported for PA fibers. ${ }^{41,46}$ The carbon nanofiber-coated wires had a larger linear range than other published fibers; for example, it has been previously reported that PA fibers demonstrate a linear range of $0.1-10 \mu \mathrm{g} / \mathrm{mL}$ for phenols. ${ }^{47}$ This attribute demonstrates the ability of the fiber to be used for a wide range of sample concentrations. 


\begin{tabular}{|c|c|c|c|c|}
\hline Fiber & Compound & $\begin{array}{c}\text { Linear } \\
\text { Range } \\
(\mu \mathrm{g} / \mathrm{mL})\end{array}$ & $\begin{array}{l}\text { Limit of } \\
\text { Detection } \\
(\mathrm{ng} / \mathrm{mL})^{\mathrm{a}}\end{array}$ & $\begin{array}{l}\text { Correlation } \\
\text { Coefficient }\end{array}$ \\
\hline
\end{tabular}

(\%)

\begin{tabular}{lccccc}
\hline $600^{\circ} \mathrm{C}$ & Phenol & $0.001-1$ & 0.01 & 0.99 & 8.8 \\
& 4-Chlorophenol & $0.001-1$ & 0.1 & 0.99 & 3.3 \\
& 4-Nitrophenol & $0.001-0.4$ & 0.03 & 0.98 & 6.7 \\
$800^{\circ} \mathrm{C}$ & Phenol & $0.001-4$ & 0.02 & 0.93 & 10 \\
& 4-Chlorophenol & $0.001-0.4$ & 0.08 & 0.97 & 10 \\
& 4-Nitrophenol & $0.001-4$ & 0.04 & 0.95 & 9.2
\end{tabular}

Table 6. Limits of detection, linear range, and correlation coefficients for the analysis of phenol, 4-chlorophenol, and 4-nitrophenol using 600 and $800^{\circ} \mathrm{C}$ electrospun-fiber coated SPME wires. ( ${ }^{a} \mathrm{k}=3$ for limit of detection calculation) 


\subsection{General Use and Stability of Fibers}

Fabrication of SU-8 electrospun coated wires is both rapid and simple when compared to other established methods for SPME fiber preparation. SU-8 coated SPME fibers can be electrospun and crosslinked in 10 minutes.

The thickness of the electrospun nanofibrous coating proved to be reproducible on a fiber-to-fiber basis. For each processing temperature, the coating thickness varied no more than $10 \%$ between fibers. There was no discernable difference between single fiber and fiber-to-fiber reproducibility; as can be seen in Figures 9 and 13, the relative standard deviation for each time point typically fell within a range of $5-15 \%$ with respect to the peak area.

Standard deviations were of the same magnitude for all analytes examined.

Each SPME fiber typically exhibited a lifetime of 20-30 extractions and desorption cycles before fiber failure occurred. Prior to failure, no fiber bleed or increased background from previously extracted analytes was observed. In most cases, fiber failure was caused by repeatedly scraping the SPME fibers against the walls of the SPME holders; as these SPME assemblies were constructed within the lab, alignment issues were frequently a problem. There was no appreciable difference in the durability between the SU-8 electrospun SPME fibers and the carbon-coated SPME fibers. 


\section{Conclusions}

A novel method of creating a fiber coated surface for SPME by using an electrospinning method was described. Electrospinning of fibers onto stainless steel wires is a simple and inexpensive coating method for SPME fibers. This method allows for a variety of controllable parameters to be exploited for SPME. The size of the fibers and the thickness of the fibers on the SPME wires are controlled by varying the electrospinning parameters. Additionally, electrospinning of fibers provides a method to create a high surface area SPME coating.

Since SU-8 can be converted to carbon via pyrolysis, the electrospun-fiber coated wires are converted to carbon at various temperatures and evaluated as SPME devices. These electrospun-fiber coated wires extracted both nonpolar and polar compounds. The fibers that displayed the best overall extraction of nonpolar compounds were the electrospun-fiber coated wires pyrolyzed at $600^{\circ} \mathrm{C}$ and $800^{\circ} \mathrm{C}$. These fibers also provided low detection limits and large linear ranges for the nonpolar compounds analyzed. For polar compounds, specifically phenolic compounds, the $600^{\circ} \mathrm{C}$ and $800^{\circ} \mathrm{C}$ electrospun fibers provided the best overall performance. The detection limits for phenolic compounds using the $600^{\circ} \mathrm{C}$ and $800^{\circ} \mathrm{C}$ fibers were slightly lower than that of the PA fiber. 
All electrospun-fiber coated SPME wires showed high thermal stability which will allow these fibers to be for a wider range of volatile compounds, especially less volatile compounds. The experimental results presented in this paper clearly demonstrate that electrospun-fiber coated SU-8, 400, 600, and $800^{\circ} \mathrm{C}$ wires are suitable for a wide range of analytes from nonpolar to polar analytes and these fibers are applicable to SPME. 


\section{References}

1. Pawliszyn, J. Solid Phase Microextraction: Theory and Practice, 1997.

2. Pawliszyn, J. Applications of Solid Phase Microextraction, Pawliszyn, J. Ed., 1999, Chap.1, 3-21.

3. Ouyang, G.; Pawliszyn, J. Anal. Bioanal. Chem. 2006, 386, 1059-1073.

4. Grote C.; Pawliszyn, J. Anal. Chem. 1997, 69, 587-596.

5. Gawdzik, B.; Sobiesiak, M.; Puziy, A.M; Poddubnaya, O.I. J. Liq.

Chromatogr. Relat. Technol. 2004, 27, 1027-1041.

6. Musteata, M. L.; Musteata, F.M.; Pawliszyn, J. Anal. Chem. 2007, 79, 69036911.

7. Grecki, T. Applications of Solid Phase Microextraction, Pawliszyn, J. Ed., 1999, Chap.7, 92-108.

8. Mani, V. Applications of Solid Phase Microextraction, Pawliszyn, J. Ed., 1999, Chap.5, 57-72.

9. Dietz, C.; Sanz, J.; Camara, C. J. Chromatogr., A 2006, 1103, 183-192.

10. Jiang, G.; Huang, M.; Cai, Y.; Lv, J.; Zhao, Z. J. Chromatogr. Sci. 2006, 44, 324-332.

11. Bagheri, H.; Mir, A.; Babanezhad, E. Analytica Chimica Acta. 2005, 532, 89-95.

12. Budziak, D.; Martendal, E.; Carasek, E. Analytica Chimica Acta. 2007, 598, 254-260.

13. Malik, A.; Chong, S. L. Applications of Solid Phase Microextraction, Pawliszyn, J. Ed., 1999, Chap.6, 73-91. 
14. Wang, Z.; Xiao, C.; Wu, C.; Han, H. J. Chromatogr., A 2000, 893, 157-168.

15. Giardina, M.; Ding, L. H.; Olesik, S. V. J. Chromatogr., A 2004, 1060, 215224.

16. Giardina, M.; Olesik, S. V. Anal. Chem. 2003, 75, 1604-1614.

17. Zeng, Z.; Qiu, W.; Huang, Z. Anal. Chem. 2001, 73, 2429-2436.

18. Zhao, F.; Meng, Y.; Anderson, J.L. J. Chromatogr., A 2008, 1208, 1-9.

19. Mangani, F.; Cenciarini, R. Chromatorgraphia. 1995, 41, 678-684.

20. Djozan, Dj.; Assadi, A. Chromatographia. 1997, 45, 183-189.

21. Liu, X.; Ji, Y.; Zhang, Y.; Zhang, H.; Liu, M. J. Chromatogr. A. 2007, 65, 1017. 
23. Boudriot, U.; Dersch, R.; Greiner, A.; Wendorff, J. H. Artif. Organs 2006, 30, 785-792.

23. Aussawasathien, D.; Dong, J.-H.; Dai, L. Synth. Met. 2005, 154, 37-40.

24. Shim, W. G.; Kim, C.; Lee, J. W.; Yun, J. J.; Jeong, Y. II; Moon, H.; Yang, K. S. J. Appl. Polym. Sci. 2006, 102, 2454-2462.

25. Luoh, R.; Hahn, H. T. Compos. Sci. Technol. 2006, 66, 2436-2441.

26. Ding, B.; Kima, J.; Miyazaki, Y.; Shiratori, S. Sens. Actuators, B 2004, 101, 373-380.

27. Moran-Mirabal, J. M.; Slinker, J. D.; DeFranco, J. A.; Verbridge, S. S.; Ilic, R.; Flores-Torres, S.; Abruna, H.; Malliaras, G. G.; Craighead, H. G. Nano Lett. 2007, 7, 458-463.

28. Pinto, N. J.; González, R.; Johnson, A.T., Jr.; MacDiarmid, A. G. Appl. Phys. Lett. 2006, 89, 033505-033505-3.

29. Ramakrishna, S.; Fujihara, K.; Teo, W.-E.; Lim, T.-C.; Ma, Z. An Introduction to Electrospinning and Nanofibers; World Scientific, 2005.

30. Steach, J. K.; Clark, J. E.; Olesik, S. V. J. Appl. Polym. Sci. 2009, in press.

31. Singh, A.; Jayaram, J.; Madou, M.; Akbar, S. J. Electrochem. Soc. 2002, 149, E78-E83.

32. Tuinstra, F.; Koenig, J.L. J. Chem. Phys. 1970, 53, 1126-1130.

33. Knight, D.S.; White, W.B. J. Mater. Res. 1989, 4, 385-393.

34. Matthews, M.J.; Pimenta, M.A.; Dresselhaus, G.; Dresselhaus, M.S.; Endo, M. Phys. Rev., B. 1999, 59, R6585-R6588.

35. Lespade, P.; Marchand, A.; Couzi, M.; Cruege, F. Carbon 1984, 22, 375385.

36. Steach, J. K. Dissertation: The Development of Novel Phases with Photoresist for Capillary Electrophoresis, Capillary Electrochromatography, and Solid-Phase Microextraction. The Ohio State University. 2008, 55-56. 
37. Shirey, R.E. J. Chromatogr. Sci. 2000, 38, 279-288.

38. Tang, B.; Isacsson, U. Energy Fuels 2008, 22, 1425-1438.

39. Almeida, C.M.M.; Boas, L.V. J. Environ. Monit. 2004, 6, 80-88.

40. Zhang, Z.; Pawliszyn, J. Anal. Chem. 1993, 65, 1843-1852.

41. Popp, P.; Paschke, A. Chromatographia, 1997, 46, 419-424.

42. Paschke, A.; Popp, P. Applications of Solid Phase Microextractions, Pawliszyn, J. Ed. 1999, Chap. 10, 140-155.

43. Fustinoni, S.; Giampiccolo, R.; Pulvirenti, S.; Buratti, M.; Colombi, A. J. Chromatogr. B. 1999, 723, 105-115.

44. Chunhui, J.; Shen, W.; Zhang, W. Talanta. 2006, 69, 894-899.

45. Buchholz, K. D.; Pawliszyn, J. Anal. Chem. 1994, 66, 160-167.

46. Buchholz, K.D; Pawliszyn, J. Environ. Sci. Technol. 1993, 27, 2844-2848.

47. Bartak, P.; Cap, L. J. Chromatogr. A. 1997, 767, 171-175. 